Aus dem histologisch-embryologischen Institute zu Innsbruck.

\title{
Über Terminalkörperchen der Anamnien.
}

\author{
Von \\ Dr. Hans Wunderer. \\ Hierzu Tafel XL-XLI.
}

Gelegentlich der Suche nach sensiblen Endigungen im Muskelsystem von Haien habe ich bei Squatina mittels Methylenblau Nervenendknäuel aufgefunden. Weitere Untersuchungen, die mit verschiedenen Methoden bei Acanthias, Squatina und namentlich bei Scyllium ausgefübrt wurden, hatten bei diesen Haien die Anwesenbeit offenkundiger Terminalkörperchen - im Sinne Krauses (1858) - ergeben; dadurch wurde ich veranlasst, die zerstreuten Angaben über Endkörperchen bei Fischen und Anamnien überhaupt zu sammeln, wo tunlich, naclizuprüfen, und wenigstens je einen Vertreter der mir zugänglichen Klassen und Unterklassen der Anamnien auf das Vorkómmen von Terminalkörperchen zu untersuchen. Dipneusten und Gymnophionen standen mir nicht zur Verfügung; Vertreter der Cyclostomen (Petromyzon) und Ganoiden (Accipenser sturio) habe ich nach verschiedenen Methoden, aber ohne Erfolg auf Terminalkörperchen untersucht; da ich auch in der Literatur keine Angaben über Terminalkörperchen der eben erwähnten Klassen, beziehungsweise Unterklassen aufgefunden habe, so gelangen sie im Folgenden nicht zur Besprechung. Die Erörterung der Terminalkörperchen erfolgt nach den Tierklassen und zwar in aufsteigender Reihenfolge; sie beginnt demnach mit den Leptocardier n (Amphioxus), dann folgen von Fischen die Selachier und Teleostier und endlich von Amphibien die Urodelen und Anuren. Die Ergebnisse der Literaturstudien enthălt der erste Hauptabschnitt, die Ergebnisse meiner eigenen Untersuchung und die kritische Besprechung der vorliegenden Angaben der zweite Hauptabschnitt. Die von mir angewandten Methoden.sind zu Beginn des zweiten Hauptabschnittes aufgeführt.

Es sei mir an dieser Stelle gestattet, Herrn Professor Kerschner für die vielen Anregungen und Ratschläge und für 
das grosse Interesse, mit welchem er den Fortgang dieser Arbeit verfolgte, den wärmsten Dank auszusprechen. Herrn Professor Cori bin ich für die grosse Zuvorkommenheit, mit welcher er mir während meines mehrmaligen Aufenthaltes an der zoologischen Station in Triest die Beschaffung des nötigen Untersuchungsmateriales erleichterte, zu innigem Dank verpflichtet.

\section{A. Geschichtlicher Überblick.}

1. Branchiostomen. Amphioxus lanceolatus.

Quatrefages (1845) fand, dass ein grosser Teil der Nerven in der Haut des Amphiox us in kleinen bläschenförmigen, ovoiden Organen mit dicker Hülle endet (Taf. XIII, Fig. 8). Sie sind nach seiner Auffassung "schleimerzeugende Krypten" (S. 229). In einer Anmerkung (S. 248) wirft er jedoch die Frage auf, ob sie vielleicht den Vater-Pacinischen Körperchen analog seien. Leuckart und Pagenstecher (1858, S. 561 u. 562) beschrieben an den Teilungsstellen der Nerven am Kopfende des Amphioxus Ganglienzellen; „hier und da erschien eine solche Zelle auch als Endpunkt eines der Zweiglein, welche als Endteilungen jener Äste. in die Haut verfolgt werden können."

Schultze (1861) untersuchte die Epidermis des Amphioxus ohne Erfolg auf das Vorkommen von Nervenendkolben. "Somit müssen hier die Nervenendkolben, wenn sie wirklich in der von Quatrefages gezeichneten Weise existieren, in der Lederhaut liegen" (S. 301, 302).

Marcusen (1864) leugnet die Endigung der Nerven in bläschenförmige Organe und erklärt diese zum Teil für Kerne, welche an Teilungsstellen der Nerven liegen, zum Teil für scbraubige Windungen von Nervenfasern.

Owsjannikow (1868) bestätigt die Angaben Marcusens insoweit, als auch er Kerne an Teilungsstellen der Nerven findet und spiralige Windungen der letzteren anerkennt; diese Bildungen seien aber keineswegs identisch mit den von $Q u a t r e f a g e s$ beschriebenen "Endkolben". Solche findet er regelmässig im Bereiche des Trigeminus an der Spitze der Ober- und Unterlippe. Dort verliert sich die Primitivfaser „in eine runde oder ovale

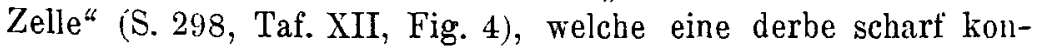
tourierte Hülle besitzt. 
Nach Reichert (1870) sind die Nervenfasern am Kopfe und am Schwanze, durch kolben- oder auch spindelförmige Anschwellungen ausgezeichnet, von denen mit Sicherheit ausgesagt werden kann, dass ibnen die Kriterien von Nervenkörpern fehlen, und dass sie sich der morphologischen Beschaffenheit nach mit den Krauseschen Endkolben vergleichen lassen" (S. 756).

Nacb Stieda (1873) bestehen die vesikulären Organe aus "Ganglienzellen, welche in dem Teilungswinkel einer Primitivfaser oder eines kleinen Bündels von Fasern eingelagert sind" (S. 50). Er fand deren nicht zu selten 2, auch 3, welche 5:7 $\mu$ maßen und einen deutlichen Kern zeigten.

Langerlians (1876) findet die fraglichen Gebilde nur im Bereiche des ersten und zweiten Hirnnerven und erklart sie für periphere Ganghenzellen, die mit einer deutlichen kernhaltigen Kapsel umgeben sind (S. 299).

Merkel (1880) bestätigt die Angaben von Langerhans bezüglich-der Natur der "vesikulären Organe." Er findet sie aber, wie $R$ eichert, wiewohl inkonstant, auch an den Schwanznerven.

Pouchet (1880) bildet (Taf. XXIX, Fig. 7, a und b) die von $Q$ uatrefages beschriebenen Körperchen als sensible Endigungen des Trigeminus $a b$. In der Figurenerklarung unterscheidet er "simple terminations with three cells", die von einer gemeinsamen kernhaltigen Hülle umgeben sind, und "compound terminations."

Krause (1881) bezieht sich in einer Anmerkung (S. 128) auf $\mathrm{P}$ o u c h e t s Abbildung (Taf. XXIX, Fig. 7, a und b). „Danach endigen bei Amphioxus lanceolatus sensible Fasern des Trigeminus mit den schon länger bekannten terminalen Körperchen. Sie gleichen am mcisten den L e y d i gschen Körperchen, zeigen aber eine dünne Hülle, die einen Kern besitzt und mehrere kernhaltige Zellen umgibt."

Rohon (1882, S. 12, Taf. I, Fig. 1 und Taf. II, Fig. 12), welcher die fraglichen Gebilde mit der Goldmethode untersuchte, erklärt sie für vielgestaltige und verschieden grosse Ganglienzellen, die von einer membranartigen und am b̈anfigsten mit oblongen Kernen versehenen Kapsel umgeben werden. "Einzelne der Ganglienzellen, als auch mehrere hintereinander", befinden "sich in continuo mit der Nervensubstanz", so dass ihm dieses 
Gebilde nals ein mit der Nervenfaser innigst vereinigtes Ganze elschien, gleichviel, ob dieser Umstand die kleinsten oder die grösseren Zellen betraf (Taf. II, Fig. 14 a. gl"). Dabei bildete die Nervenscheide eine Kontinuität mit der Kapsel der Zelle" (S. 13).

Krause (1885) bezeichnet nummehr in einer kurzen, nicht vollständigen Zusammenstellung der bis dahin für Amnioten vorliegenden Angaben über Terminalkörperchen die in den vermeintlichen Endkörperchen befindlichen Zellen als Kolbenzellen.

$\mathrm{Kr}$ a u se (1888) erklärt die Körperchen von Quatrefages für Terminalkörperchen. Sie bestehen naus einer oder zwei kernhaltigen, eiförmigen oder etwas abgeplatteten Zellen und einer Hülle, die mit der kernhaltigen Scheide der zutretenden Nervenfaser gleichwie die Zellen mit letzterer selbst zusammenhängen" (S. 146). Sie erinnern an die seinerzeit von Kölliker (1853) beschriebenen Nervenendigungen in der Haut des Chauliodus (s. Abschn. A, II b).

Fusari (1889) findet die Struktur der von Quatrefages entdeckten Körperchen „ziemlich einfach; sie sind aus einer, zwei, drei resp. vier mit einem stark granulierten Protoplasma und einem grossen Kern versebenen Nérvenzellen zusammengesetzt. Diese sind in eine Scheide gehüllt, die ihrerseits eine Fortsetzung der besonderen Scheide der Nervenfasern ist; fermer bemerkt man zwischen diesen Zellen und der Hülle ein Endothel von schaligen Zellen. Die Nervenfaser dringt in diese Körperchen ein und steht mit den Nervenzellen in direkter Verbindung. An jenem Teile dieser Körperchen, welcher gegen die Peripherie zu sieht, nehmen eine, zwei und auch drei Nervenfasern ihren Ursprung." Diese „können . . . andere ähnliche kleine Körperchen enthalten und so anderen Fasern zum Ursprung dienen" (S. 137).

D o giel (1903, Taf. XXII-XXIII, Fig. 24, 30, Taf. XXIV und XXV, Fig. 23), welcher das periphere Nervensystem des Amphioxus mit Hilfe von Methylenblau untersuchte, konnte an den von Quatrefages entdeckten Zellen ,in vielen Fällen, besonders wenn die Zellen einzeln gelagert sind, . . . wahrnehmen ... . dass von denselben ein dünner Fortsatz abgeht, welcher unmittelbar in ein Nervenstämmchen übergeht (Fig. 24 b). Welcher Kategorie von Zellen die genannten Gebilde zugezălılt werden müssen, ist vorlăufig schwer zu sagen; nichtsdestoweniger muss jedoch bemerkt werden, dass dieselben durchaus den kleinen 
Gebilden, welche an den Verzweigungen der dorsalen und ventralen Äste sämtlicher übrigen Spinalnervenpaare gelagert sind, ähneln." Letztere erklärt Dogiel für Spinalganglienzellen.

\section{Pisces.}

a) Selachier.

1. Squaliden.

Über die von mir im Jahre 1903 bei Haien gefundenen Terminalkörperchen hat Professor Kerschner der wissenschaftlichen Ärztegesellschaft in Innsbruck kurz berichtet. Das Referat des Sitzungsberichtes (15. Mai, Wien. Klin. Wochenschr. Nr. 35) lautet:

„Professor Kerschner demonstriert:

3. Vom Assistenten H. W und e rer in den Brusttlossen bei Scyllium, Acanthias und Squatina aufgefundene (mit Goldchlorid und Methylenblau dargestellte), verschieden gestaltete (runde, ovale, cylindrische, konische) T'erminalk ö rperchen, deren Grösse zwischen 50 und 600 Mikren schwankt, und die in Form und Bau den vom Vortragenden beschriebenen Sehnenendkolben mit marklosem Nervenknäuel, zúm Teil auch den Konjunktivalendkolben gleichen.

Dieselben zeigen als Fortsetzung der Nervenscheiden:

a) Eine mitunter sehr zarte, undeutlich streifige, kernarme äussere Hülle;

b) ein inneres bindegewebiges Gerüst in Form eines echten kernreichen Retikulums, welches die zahlreichen Windungen des marklosen Geăstes einscheidet. Letzteres entsteht durch wiederholte dichotomische Teilung eines oder zweier markhaltiger Nervenfasern, welche bald nach dem Eintritt ihre Markscheide abstreifen; die langen, nahe der Oberfläche verlaufenden varikösen Terminalfasern kreuzen sich vielfacl, gehen aber keine Anastamosen ein und scheinen frei zu enden."

\section{Rajiden.}

Von den verschiedenen Formen der "Sehnenendorgane", welche Pansini (1888) bei Torpedo beschrieb, kommen für die vorliegende Untersuchung zwei in Betracht.

Erstens Gebilde, welche er nicht gar băufig in der Rückenaponeurose fand, von ovaler, elliptischer oder runder Gestalt, 
$90-140 \mu$ Länge und 40-85 $\mu$ Breite. "Sie sind nach Grösse, Aussehen und scharfer Abgrenzung gegen das vorliegende Sehnengewebe wahre Terminalkörperchen" (S. 147). Diese Sehnenendplatten (piastre neurotendinee) entstehen durch ein- oder zweimalige Teilung einer oder zweier Nervenfasern in zwei bis drei noch markhaltige Äste, und deren marklose Verzweigung, die derart angeordnet ist, dass die Enden der Terminalfasern beinahe gleich weit vom Mittelpunkte der Platte entfernt sind, welch letzterer ungefähr der ersten Teilungsstelle der Markfaser entspricht. Die marklosen Zweige tragen in ihrem Ferlaufe und namentlich an ihrem Ende kleine granulierte Kerne; dem Umfang der Platte entlang finden sich unter einer Art Hülle, welche die ganze Platte zu begrenzen scheint, grosse Kerne, ahnlich solchen von Ganglienzellen. Pansin i hebt noch besonders die grosse Ähnlichkeit dieser Sehnenendplatten mit den grossen motorischen Endplatten von ' $\mathrm{T}$ o r p e d o hervor, und sieht beiderlei Platten als „histomorphologisch aequivalente" Bildungen an.

Zweitens der vereinzelte Befund, wo an einem ovoiden Sehnenabschnitt der Brustflosse, welcher einem "Golgischen Körperchen" (Selınenspindel) glich, die primären Teiläste zweier" Markfasern in kernreichen Plättchen endigten.

Purvis (1890) beschreibt und zeichnet aus dem M. sacrolumbalis von $R$ aja clavata nach Goldpräparaten Nervenendorgane (Taf. XXXV, Figg. 1-4), die folgende Bestandteile zeigen: 1. eine meist ovale Kapsel, die Fortsetzung der äusseren Nervenscheide; 2. einen Achsenteil, die mehr oder weniger gewundene Fortsetzung des Achsenzylinders, der mit einer gewöhnlich birnförmigen oder kugeligen Anschwellung, bisweilen aber deutlich hakenförmig endet; 3 . einen protoplasmatischen Anteil, bestehend aus hellem Protoplasma, welches den Raum zwischen Achsenzylinder und Kapsel ausfüllt. Als aussergewöhnliche Befunde werden an solchen Gebilden die Anwesenheit eines spiralig gewundenen Fadens an der Aussenseite oder unmittelbar an der Innenflache der Endkapsel, und in einem Falle die Einmündung von drei bis vier Nerven in eine gemeinsame Kapsel angeführt.

\section{b) Knochenfische.}

Ich führe zuerst jene Arbeiten auf, welche die offenbar epithelialen Endorgane von Stomias und Chauliodus behandelnoder auf sie Bezug nehmen. 
Kölliker (1858) beschrieb bei Stomias barbatus in der ganzen Haut des Rumpfes als Nervenendkörperchen, „ganz ăhnliche Bildangen“ (S. 28), wie er sie früher (1853) bei dem nahe verwandten Chauliodus gefunden. Dieselben sind rund, länglich oder birnförmig und gewähren "mit ihren Nerven das Bild mit Blättern oder Früchten besetzter Bäumchen (Taf. I, Fig. 3, 2.). Ausnahmsweise kommen absonderliche Formen vor, die an die Verhaltnisse der Pacin ischen Körperchen erinnern" (S. 29). Die Körperchen besitzen eine zarte homogene Hülle, die sich in das ähnlich beschaffene Neurilemm der Nervenfaser fortsetzt. „Innerhalb dieser Hülle und derselben fast überall dicht anliegend findet sich eine zweite zarte Blase, die mit eigentümlichen, runden oder lünglichen Körpern vollgepfropft ist" "S. 30). Kölliker glaubt diese Körper als Zellen ansprechen zu dürfen, die „eine dem Fett des Nervenmarkes sehr ähnliche Substanz zu führen" scheinen. Die zu den Körperchen tretenden Nervenfasern „scheinen mit der inneren, die eigentümlichen Zellen enthaltenden Blase sich in Verbindung zu setzen" (S. 30, 31). Bei Chauliodus, auf welchen sich Kölliker bezieht, fand er (1853) in der Gallertlage der Haut "eine grosse Zahl kugelrunder kleiner Körper ganz vom Bau einfacher Drüsenblăschen, mit einer deutlichen Membrana propria, einem mehr zylindrischen Epithel und einer runden Öffnung, die höchst wahrscheinlich nach aussen mündet“ (S. 366 und 367). Zu jedem dieser Bläschen liess sich eine ausserst dünne, marklose Nervenfaser hin verfolgen, die in der Membrana propria leicht angeschwollen endete. Kölliker glanbte diese Bildungen den "Nervenknöpfen" in den Schleimkanälen vergleichen $z u$ müssen, ohne die Annahme, dass sie die Bedeutung von Drüsen bätten, widerlegen zu können.

L e y d ig (1879) beschrieb in der Lederhaut von Chauliodus Sloani als "pigmentlose Organe" geschlossene blasige Gebilde mit einer Tunica propria und einem zelligen Inhalt, der sich in eine zentrale und periphere Partie sondert. Die erstere besteht aus etwa fünf grösseren rundlichen Zellen mit blasigem Nucleus, der noch einen Nucleolus besitzt. Die peripherischen Zellen sind zu einer Reihe geordnet, um vieles kleiner und zylindrisch. „An alle Organe dieser Art geht eine Nervenfaser heran und verbindet sich mit der Blase so, dass ihr Ende auf den grosszelligen Innen- 
körper stösst" (S. 376). Eine Öffnung an diesen Gebilden lat er nicht zu erblicken vermocht. Leydig stellt diese Gebilde scinen "mit Pigment ausgestatteten Organen" desselben Tieres an die Seite, reibt sie unter die "Organe des sechsten Sinnes" ein und vergleicht sie mit den "Endorganen von Halltnerven der Salamandra und des Menopoma", die er als Verwandte der Vater-Pacinischen Körperchen und der Endkolben in der Conjunctiva bezeichnet hatte (s. Abschn. A. IIIa).

Ussow (1879), welcher die „augenähnlichen Flecken" auch von Stomias und Chauliodus untersuchte, erwähint, Kölliker habe wohl bei genannten Fischen "gewisse Gebilde, welche offenbar 'Tastorgane waren“, untersucht, lasse aber die "augenahmichen Flecken ganz bei Seite".

Brock (1887) gegenüber, der auf die „beiden einzigen Angaben über Tastkörperchen ähnliche Nervenendigungen bei Fischen, welche von Kölliker herrühren" (S. 310), hinwies, behauptet L ey dig (1888) die Identität der ron Brock erwähnten Gebilde und der von ihm beschriebenen und abgebildeten (1879, Taf. XV, Fig. 8) „Hautsinnesorgane ohne Pigment" aus der Haut des Chauliodus. Alles, was daran feśtgestellt werden konnte, hätte zu der Annahme geführt, dass diese "hellen Organe“ und die pigmentierten oder "Nebenaugen" verwandtschaftlich zusammengehören (S. 41).

Nun lasse ich die übrigen Angaben über Terminalkörperchen bei Teleostiern folgen:

Leydig (1883) beschrieb bei Lobocheilus im Knopfe von Hautpapillen "ein nervöses Endgebilde, . . welches man wohl auf eine Gruppe von Nervenendkolben deuten darf." $\mathrm{Er}^{\circ}$ findet nämlich innerhalb einer äusserst feinkörnigen, mehrfach eingekerbten Masse „eine Anzahl gekrümmter stabartiger Gebilde von scharfem Umriss und mit dem einen Ende nach abwärts gegen den Nerven der Papille biegend" (S. 11, Taf. II, Fjg. 17). Der Umstand, dass ein solcher Stab und eine Partie der feinkörnigen Substanz ein Ganzes zu bilden scheinen, veranlasse ihn, von Nervenendkolben zu sprechen, deren Bau sich aber nur an den grösseren Papillen soweit, als angegeben wurde, erkennen liess.

Brock (1887) fand bei Gasterotokeus biaculeatus, einem Lophobranchier, in Papillen eines in der Aftergegend befindlichen Polsters, des "Tastkissens, ... . eine Menge Tast- 
körperchen ähnliche Gebilde...., welche in ihrer länglich elliptischen Form und durch eine deutliche Querstreifung ausgezeichnet, eine bemerkenswerte Parallele zu den Tastkörperchen der höheren Vertebraten zu bilden scheinen (S. 302). . . D Die vermutlichen Tastorgane, .... gehören zwei verschiedenen Formen an, wonach man sie als Tastkörperchen und Endkolben unterscheiden kann" (S. 305). Die Tastkörperchen finden sich ausnahmslos in der Spitze der Papillen; sie sind ganz aus Zellen zusammengesetzt und man kann "eine Art äussere Hülle und einen Innenkolben unterscheiden" (S. 306); jene besteht aus sternförmigen pigmentierten Zellen, dieser aus pigmentlosen, senkrecht zur Längsachse des Tastkörperchens aufeinander geschichteten, im Querschnitt sternförmig verăstelten Zellen. Bei der Beschaffenheit des Materials konnte er zu den Tastkörperchen keine Nerven verfolgen. "Die Endkolben sind den gleichnamigen Gebilden der hölıeren Vertebraten ganz ausserordentlich ähnlich" (S. 308). Sie finden sich an der Basis der Papillen und sind von ovaler, oft der Kugelgestalt sich nähernden Form. Zwischen der pigmentierten Hülle der Körperchen und dem "Endkolben", welcher aus einer homogenen leicht granulierten Masse besteht, ist deutlich ein feiner Raum sichtbar. Öfters sah Brock ,ein fadenähnliches Gebilde, welches grosse Ähnlichkeit mit einer doppelt-kontourierten Nervenfaser hatte, von der Basis der Papille her an einen Endkolben herantreten, ohne diese vermeintlichen Nerven in das Innere des Endkolbens" (S. 309) verfolgen zu können.

Leydig (1888) erklärt die "Tastkörperchen" von Brock für die von ihm schon im Jahre 1883 beschriebenen Lymphrăume. Die Endkolben Brocks seien identisch mit den von ihm bei L o b o c heilus (1883) aufgefundenen gleich gedeuteten Bildungen.

Krause (1888) bestreitet auf Grund der Präparate Brocks die Ähnlichkeit der von Leydig beschriebenen Lymphgefässe mit den "scharf umschriebenen Tastkörperchen von Gasterotokeus". „Dass keine Nervenfasern mit Bestimmtheit nachgewiesen werden konnten, fällt an Spirituspräparaten und bei der notorischen Feinheit der sensiblen Nervenfasern in der Fischbaut überhaupt wenig ins Gewicht (S. 147).

v. Mährenthal (1892) berichtet über Tastkörperchen in höckerförmigen Erhebungen an der Oberseite der Kopfhaut der 
Koppe (Cottus Gobio L.): sie liegen in Papillen und bestehen aus scheibenförmigen und säulenartig übereinander gelagerten Zellen; zu diesen liess sich bei einem mit Osmiumsäure behandelten Präparate ein Nervenstämmchen hin verfolgen, das zwischen den Zellen des Tastkörperchens in stark geschwärzten Platten sein Ende fand,

\section{Amphibien.}

a) Urodelen.

Hyrtl (1865, S.119,120) berichtet, dass bei Cryptobranch us Hautnerven des Schwanzes zu vereinzelten $\mathrm{V}$ a t e $\mathrm{r}-\mathrm{P}$ a c i n i schen Körperchen hintreten; er habe als erster deren Anwesenheit bei Crypt obranchus und bei den Amphibien überhaupt festgestellt.

Leydig (1876, b) glaubt Nervenendorgane im Schwanze der Larve von Salamandra maculosa und bei Menopoma gi g a n t e u m gefunden zu haben. Sie stellen beim Salamander geschlossene, bindegewebige Kapseln von gleichmässig rundlicher Form dar; ihr Inhalt ,scheint . . . eine gleichmässige Zellmasse zu sein“, in deren Mitte sich „eine grosse kugelige Partie . . . , welche von zarter Beschaffenheit und feiner Körnelung ist", unterscheiden lässt. Da sich der Nerv durch die Kapsel zu diesem "körnigen Zentralkörper" verfolgen lässt, fasst L e y dig letzteren als Endkolben oder terminale Ganglienkugel auf. Auch bei Ve n opoma nimmt er einen Zusammenhang der Gebilde mit Nerven an und meint, sie seien als "Verwandte der V at e rschen Körperchen, noch mehr vielleicht als Abänderungen der Endkolben aus der Konjunktiva der Säugetiere" (S 126) anzusehen.

Bei Beschreibung der Nebenaugen von $\mathrm{Chauliodus}$ Sloani kommt Leydig (1879) auf diese nunmehr ganz entschieden als Endorgane bezeichneten Gebilde im Schwanze von S a l a m a n d e rlarven zurück und weist auf den geringen Unterschied zwischen beiden Bildungen hin, der darin besteht, dass $\mathrm{Cb}$ a u li od us einen grosszelligen Innenkörper" besitzt, während bei $\mathrm{S}$ a l a mand $\mathrm{ra}$ an gleicher Stelle nur ein „körniger Zentral-

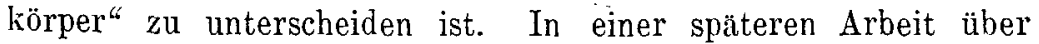
denselben Gegenstand fasst L e y dig (1881) die „augenähnlichen Organe" und die mit diesen in Zusammenhang gebrachten Apparate aus dem Schwanze von M enopoma und Salamandra als "pseudoelektrische oder wirklich elektrische" (S. 92) Organe auf. 
Ma urer (1895) fand in der Haut eines erwachsenen Cryptobranchus neben "Hautsinnesorganen" Hautpapillen, von deren Spitze eine "hornige Masse" in die Epidermis fast bis zur freien Oberflache sich erstreckt (Taf. VI, Fig. 6). „Dieses Bild . . . . ist an sich unverständlich, es wird aber leicht erklärt, wenn man.... es mit Fig. 5 (Abbildung eines Hautsinnesorganes) vergleicht und das Hautsinnesorgan herausgestossen denkt" (S. 175). Dabei sollen nach $\mathrm{M}$ a u rers Vorstellung nur die „birnförmigen Sinneszellen " ausgestossen werden, die „Stützzellen" aber zurückbleiben und unter Beteiligung der benachbarten Epithelzellen „jenen Hornklumpen" bilden, der schliesslich auch ausgestossen werde, so dass "nach gănzlicher Ausstossung eines Hautsinnesorganes sich eine zarte Epidermislage darüber geschlossen hat, welche aus einer einfachen Lage plasmatischer Zellen und einer einfachen Schicht verhornter Zellen besteht (S. 180). An diesem dünnen Epidermisbezirk trete "auf einer an der Spitze sehr verbreiterten Papille weitere stärkere Zellvermehrung und Verhornung" ein, so dass auch in die Papille hinein ein Komplex platter verhornter Zellen vorrückt, „die schliesslich unter Verschwinden der Zellgrenzen und der Kerne unregelmässige Schollen von Hornsubstanz auf der Papille aufsitzend darstellen. In gewissen Stadien zeigen solche Gebilde eine überraschende Ähnlichkeit mit den. Tastkörperchen der Lederhautpapillen der Säugetiere" (S. 180). Auf S. 195 berichtet H a urer über diesen Gegenstand weiter: „Bei Cryptbranchus habe ich genauer die Eliminierung von Hautsinnesorganen geschildert und dargestellt, wie an deren Stelle epidermoidale Elemente in die Tiefe rücken und sich von der Epidermis ablösen können. Solche führen zur Bildung von Tastlkörperchen. Fragen wir nach der Herkunft dieser Zellen, so sind dieselben zum Teil Zellen der das Hautsinnesorgan umgebenden Epithelzellen. Dann wird kein wahres Tastkörperchen gebildet. Ein solches entsteht nur dann, wenn an einer bestimmten Stelle ein Hautsinnesorgan nicht zur Ausbildung kommt. Solche wahre Tastkörperchen können sich also nie bilden, wenn an einer Stelle ein Hautsinnesorgan ausgestossen wurde."

Krause (1903) reiht die Endorgane Leydigs von Salamandra und Menopoma unter die Seitenorgane ein, stellt jedoch ihre Zugehörigkeit $z u$ denselben als zweifelhaft hin. 


\section{b) Anuren.}

Von Bildungen, welche bei den Anuren als "Terminalkörperchen" beschrieben oder mit solchen in näheren Zusammenhang gebracht worden sind, wie die Merkelschen Tastflecke, haben nur diese und die „Leydigschen Körperchen" (Krause, 1876, S. 525) die Aufmerksamkeit einer grösseren Anzahl von Untersuchern auf sich gelenkt; der Übersichtlichkeit halber werde ich die Angaben über diese beiden Gebilde gesondert von den übrigen Angaben über Terminalkörperchen bei Anuren in eigenen Abschnitten anführen.

\section{Leydigsche Körperchen.}

Hensche (1856, S. 279) denkt in Berücksichtigung des Wertes, den der Daumenballen des Froschmännchens für den Begattungsprozess besitzt, an die Möglichkeit, dass die hier gelegenen Cutispapillen, zu welchen er Nerven hin verfolgen konnte, „Gefühlswärzchen" seien.

Leydig (1856) beschrieb und zeichnete (S. 155, Taf. V, Fig. 1 B) daselbst einen ovalen "Körper, der in Lage und Aussehen nicht geringe Ähnlichkeit mit einem Tastkörperchen hat." Derselbe besteht aus einem "Nervenglomerulus": einem Knäuel, welchen die Nervenfaser in der Spitze jeder Papille bildet. Hăufig ist aber „in Folge der Präparation das Bild derartig verăndert, dass anstatt der queren und geschlungenen Linien des Nervenknäuels sechs und mehr rundliche Klümpchen, zu einem Haufen zusammengeballt, das Tastkörperchen vorstellen" (Taf. V, Fig. 1 d). Krause $(1858$, S. 40) bestatigte die Anwesenheit von Endkörperchen an den genannten Orten. „Es . . . sind knäuelförmig gerollte, äusserst feine Nervenfibrillen, die, immer einzeln, in ein terminales Körperchen eintreten."

Krause (1860, S. 140-142) macht die Angabe, dass die von Leydig beschriebenen "Tastkörperchen" nur ungefähr im zehnten Teil der Papillen vorkommen. Im Gegensatz zu Ley dig fand er aber, „dass ein mehrfach sich windender Nerv in ein kleines Terminalkörperehen (Taf. I, Fig. 5 b) eintritt", das nicht "ganz und gar aus einem Nervenglomerulus" besteht, sondern ausserdem einige Körnchen erkennen lässt. An andern Körperstellen des Frosches ist es ihm „nur zweimal gelungen, einmal in der Nickhaut, ein anderes Mal am Rumpfe ganz kleine, un- 
deutliche Knäuel am Ende einer feinen Nervenfibrille wahrzunehmen". Die übrigen Papillen enthalten nichts "als einzelne quer und schrăg gestellte Kerne" (S.' 140, Taf. I, Fig. 5 e).

Krause (1861) berichtet bezüglich der von Leydig entdeckten und von ihm bestätigten Terminalkörperchen in der Daumendrüse des männlichen Frosches, dass es weder Leydig noch ihm gelungen sei, "den eigentlichen Modus der Nervenendigung in solchem dichten Knäuel allerfeinster Nervenfasern" (S. 49), um welchen er noch eine zarte Hülle zu sehen glaubt, nachzuweisen.

Ciaccio (1867) findet (S. 43, Fig. XXVIII-XXX) in den Papillen am Daumenballen des Froschmannnchens ein Flechtwerk von Nervenfasern mit eingeschalteten und damit verbundenen bipolaren und multipolaren Nervenzellen; dasselbe steht in Verbindung mit einem unter dem Kapillarnetz gelegenen Geflecht zartester, blasser Nervenfasern. Dieses Bild finde sich während der Laichzeit; ausser derselben seien die Zellen als sehr kleine Scheiben übereinander geschichtet und einander sehr nahe gerückt.

Langer (1867, S. 598) macht darauf aufmerksam, dass im Daumenballen des Frosches möglicher Weise eine Verwechslung der Blutkapillarschlingen mit "terminalen Nervenbläschen " stattfinden könnte.

Leydig (1868) glaubt auch in den Cutispapillen von Bombinator igneus "Tastkörperchen" gefunden zu haben. Sie sind gut abgrenzbar und kernähnlich, „im Sinne wie Kern und Schale einer Frucht" (S. 34, Anm.). An diesen Gebilden kann man bei gewöhlichen Vergrösserungen kaum etwas weiteres erkennen, "ausser dass man im Innern eine Anzahl an Nuclei erinnernde Punkte bemerkt". Erst bei Besichtigung mit der Tauchlinse erbält man "den Eindruck, als ob es sich um ein kleines Tastkörperchen handle; und zwar von der Art, wie sie sich in den Fingerbeeren des Menschen finden". Dieses ovale, rundliche Körperchen ist vom Rande her gezackt und eingeschnitten, oder wie in Abständen von ,etwas Faserähnlichem" umsponnen. "In den Stiel der Papille hinein erstreckt sich eine lichte Zeichnung, welche auf das Ende eines Nerven ausgelegt werden könnte" (S. 35, 'Taf. I, Fig. 1 A).

Eberth (1869, S. 13) fand einen Teil der Bindegewebszellen in den. Papillen des Daumenballens vom Frosche stern- 
förmig, konnte aber keine Verbindung derselben mit Nervenfasern auffinden.

Leydig (1872) kommt bei der Beschreibung von "Tastkörperchen " der einheimischen Nattern auf die des Daumenballens beim Frosche zurïck und glaubt in seiner ursprünglichen Abbildung (Fig. 1 Bb, 1856) die Oberfläche des Tastkörperchens zu erblicken. während er die queren und geschlungenen Linien, welche er seinerzeit als Windungen des Nervenknäuels deutete, nunmehr auf die Elemente des Neurilemms bezieht; in Fig. d möchten die "sechs und mehr rundlichen Klümpchen" Teilen entsprechen, welche ihm „bei den Nattern dẹ Eindruck von kleinen Endkolben machen" (S. 352). Den Ausdruck „Endkolben“ gebraucht Leydig nicht im Sinne Krauses, sondern versteht darunter anscheinend nur kolbenförmige Endanschwellungen von Nervenfasern.

Leydig (1876a) dehnt seine Angaben dahin aus, dass diese Bildungen bei allen einheimischen Arten der Gattung Rana, ferner bei Bufo vulgaris, Bufo calaminta, Bufo variabilis, Pelobates fuscus, und Alytes obstetricans am Daumenballen und an andern Stellen, so am Rücken vorkommen. Seine Bemühungen, in den feineren Bau der Tastkörperchen einzudringen, haben ergeben, dass sie sich isolieren lassen, wobei sich zeigte, dass die Bindesubstanz der Papille schalig das Körperchen umgiebt und daher im leeren Zustande gleich einem Becher sich ausnimmt, und dass "das herausgefallene Körperchen einem Zellenkern ähnelt; dem noch etwas von einer zelligen Substanz anbaftet" (S: 153). Er glaubt deshalb, dass seine „Endkolben“ richtiger als „Endganglienkugeln" zu bezeichnen seien. Derselbe Forscher (1876 b) spricht sich über die Natur der "Tastkörperchen" auch des Frosches bestimmter aus, indem er sagt, es sei ihm nach und nach immer wahrscheinlicher geworden, um nicht zu sagen gewiss, dass Terminalganglienkugeln den wesentlichen Teil des Tastkörperchens ausmachen" (S. 521).

Merkel (1880, S. 110 u. 111) konnte zu dem als Leydigsches Körperchen bezeichneten Zellhaufen in den Papillen des Daumenballens des Frosches keine Nerven hin verfolgen und schliesst sich bezüglich der Deutung der darin vorkommenden Zellen Eberth an. Er beschreibt aber an andern Hautstellen Tast- 
zellengruppen, "Tastflecke" (s. Abschn. A, III. b. 2), welche mit den Leydigschen Körperchen nicht identisch seien.

$\mathrm{Kr}$ a u se (1881) hält trotz der angeführten gegenteiligen Äusserungen an der früheren Auffassung der L eydigschen Körperchen fest. Sie bestehen "aus einer kleinen Anzahl unregelmässig gestalteter Kerne, die vermutlich in Zellen eingeschlossen sind. Zwischen denselben windet sich eine sebr feine Terminalfaser hindurch. . . . Die Körperchen besitzen eine dünne Bindegewebshülle“ (S. 115).

Merkel (1881) konnten erneute Beobachtungen "der $\mathrm{Kr}$ a u seschen Ansicht nicht günstiger stimmen " (S. 526 u. 527), weshalb dieser Streitpunkt einstweilen unerledigt bleiben müsse.

Mazz on i (1887) fasst die Zellen der Papillen am Daumenballen des männlichen Frosches als Tastzellen auf, an welchen die Nerven mit einer knöpfchenförmigen Anschwellung enden (S.27S).

$\mathrm{Bunge}$ (1892) beschreibt am Daumenballen des Froschmännchens unter Hinweis darauf, "dass Leydig in die Coriumpapillen typische Tastkörperchen verlegte, während Eberth und Werkel hier nur Bindegewebe und keine nervösen Apparate entdecken konnten" (S. 18), Nerven, welche-durch die Papillen ins Epithel verfolgt werden konnten; auf eine Deutung der „L e y digschen Körperchen" lässt er sich nicht ein.

L e y d ig (1892) hält an der Existenz von "Tastkörperchen" in den Papillen des Daumenballens vom Froschmännchen fest, ohne neue Beobachtungen beizubringen.

Eberth und Bunge (1893) konnten mittels der Methode von Grolgi feine Nervenfasern durch die Papillen ins Epithel verfolgen. Dieselben stammen entweder direkt aus dem oberflächlichen Nervenplexus, oder es schalten sich "Endzellen" ein, vơn denen Fortsätze abgehen, welche in die Epidermis aufsteigen. Die Forscher neigen der Ansicht $z u$, dass diese Endzellen nicht nervöser Natur sind, sondern als „Scheidezellen“ (S. 198) der terminalen Fasern aufzufassen seien, ohne sich entschieden gegen die erstere Deutung auszusprechen. An den "Papillenzellen“ konnten sie trotz deren grosser Ähnlichkeit mit gewissen Sinneszellen nie Nerven finden (S. 197).

2. Merkelsche Tastflecken.

M erkel (1880) beschrieb beim Frosche an der Fusssohle und auf der ganzen Oberseite des Körpers, am dichtesten an 
den hintern Extremitäten als "Tastflecken" Gruppen von Zellen, welche unter dem Epithel in der Cutis liegen und einen ziemlich dicht gedrängten Haufen bilden, der an derselben entweder discusartig gestaltet keine Niveauveränderung herbeiführt, oder als flaches Kugelsegment eine papillenartige Vorwölbung bedingt. Eine Umhüllungsmembran fehlt diesen Haufen vollständig. Die einzelnen Zellen sind platte verhältnismässig dicke, durch wenig gewöhnliches Bindegewebe von einander getrennte Scheiben, mit welchen die Äste der von unten oder von der Seite zutretenden doppelt konturierten Nervenfasern in Verbindung treten. Diese letzteren verlieren in einiger Entfernung vom "Körperchen" ihre Markscheide und senken sich unter wiederholten Teilung in den Zellhaufen ein. Merkel meint, dass sämtliche den Tastflecken bildende'Zellen "zum Nervensystem zu rechnen sind“ (S. 110).

Nach Kra u e (1881) sei es nicht zu bezweifeln, dass die V e rke lschen Tasttlecken mit den L e y digschen Körperchen im wesentlichen übereinstimmen. Sie scheinen sämtlich „aus Querkolbenzellen zusammengesetzt zu sein, doch ist ihr feinerer Bau keineswegs genügend aufgeklärt" (S. 115).

Nach Mazzoni (1887, S. 278-279) finden sich in den Merkelschen Tastflecken nur Tastzellen, an welchen, ahnlich wie in den Papillen des Daumenballens, die marklosen Nerven mit knöpfchenförmigen Anschwellungen enden.

Huber (1887), welcher die "Brunstwarzen" von $\mathrm{Rana}$ temporaria untersuchte, findet eine auffallende Übereinstimmung derselben "mit den ron Merkel bei Rana esculenta L. beschriebenen Tastflecken, sowohl in ihrer Anordnung wie in ihrem histologischen Aufbau. . . . Die Zellen, die in das Bindegewebsgerüst der Warze besonders peripher eingebettet sind, gleichen genau den Tastzellen Merkels sind aber bedeutend zahlreicher wie diese. Indessen gelang es . . . nicht, Nerven mit absoluter Sicherheit bis zu denselben zu verfolgen" (S. 667). Die Osmium-Essigsăurebehandlung Merkels liess zwar in die Papillen aufsteigende Fibrillen deutlich erkennen, doch vermochte er sich weder von deren Zusammenhang mit den Zellen, noch überhaupt von ihrem nervösen Charakter zu überzeugen. Nur mit der Goldbehandlung (Taf. 35, Fig. 4) sei es ihm in einzelnen Făllen geglückt, den Zusammenhang jener Zellen mit Nerven wenigstens sehr wahrscheinlich zu machen. 
Eberth und B unge (1893) stellen die nervöse Natur der Y e rke l schen Tasttlecken deshalb als fraglich hin, weil es ihnen nie gelungen ist, Nerven bis in die fraglichen Zellgruppen zu verfolgen, während sie doch in deren nächsten Nähe intraepitheliale Nerven aufinden konnten.

Ma urer (1895) unterscheidet beim Frosch (Taf. V, Fig. 12) in einem saftreichen Polster, welches aus dem lockeren subepithelialen; $z$ wischen Oberhaut und straffer Lederhaut gelegenen, beträchtlich verdickten Bindegewebe besteht, zwei Arten von Zellen; einmal "einige spindelförmige und verästelte Bindegewebszellen mit kugeligen oder ovalen grossen Kernen. Dieselben sind in einer homogenen glänzenden Grundsubstanz eingelagert, die nur spärliche Fasern enthält"; als zweite Art führt er beachtenswerte, dicht der Basalfäche der Epidermis angeschlossene Zellen auf. „Sie sind zum Teil kugelig und liegen dann frei nebeneinander, zum Teil liegen sie fest aneinander gepresst und platten sich gegenseitig $a b^{3} ;$ (S. 151, 152). Nur diese letztgenannten Elemente hält er für die von Merkel beschriebenen Tastzellen. Man könne leicht einen zu ihnen hin verlaufenden Nerven nachweisen.

3. Angaben über andere Terminalkörperchen bei An uren.

Will (1850) erwähnt, er habe „beim Frosche im Gekröse zweimal Gebilde gefunden, welche Vat e r schen Körperchen vollkommen glichen". (S. 224.)

Helfreich (1870) gibt an, dass er einmal in der Konjunctiva des Frosches eine den Endkolben ganz ähnliche Bildung gesehen habe.

Sachs (1875, S. 414-416, Taf. XI, Fig. 4) beschreibt und zeichnet "Sehnenendkolben " aus der Sternoradialsehne des Frosches, welche er nur in zwei Fällen geseben hat. In das Körperchen dringen mehrere markhaltige Nervenfasern ein, welche als blasser Faden innerhalb des Kolbens aufsteigen und mit einer bläschenförmigen Bildung endigen. Die Umhüllung des ganzen Körperchens bestehe aus einer bindegewebigen Substanz mit Kernen und elastischen Bestandteilen.

Te Gempt (1877) konnte solche Endkolben nicht auffinden, ebensowenig $\mathrm{K}$ ers chner (1888). 
L o ewe (1879, S. 615) sah beim Frosche im „Bindegewebe, das die Beugesehnen der Handwurzel bedeckt . . . . sowie an den Fingergelenken hin und wieder, immerhin aber selten einige Körperchen" von spindeliger Gestalt; "die beiden Stiele der Spindel sind von homogener glasheller Beschaffenheit und gehen unmittelbar in das umgebende Gewebe über. Unmittelbar da. wo sich die Stiele an das.Körperchen inserieren, nimmt letzteres eine faserige Struktur an ..... In der Mitte der Spindel ..... befindet sich eine Verdickung und Verdunklung der Substanz des Körperchens. Letztere rührt von einer Kernenzone her, indem in der Mitte der Längsachse der Spindel sechs bis acht Kerne bintereinander gestellt sind, welche die ganze Dicke des Körperchens durchsetzen ". Er ist geneigt, diese Bildungen, an die er markhaltige Nervenfasern dicht heran verfolgen konnte, für Nervenendorgane, vielleicht für Gelenknervenkörperchen zu halten und wird in dieser Deutung durch die vermeintlich grosse Ïhnlichkeit zwischen seinen Körperchen und den von Golgi beschriebenen „Muskelsehmenorganen" bestärkt. Der Unterschied beider Beschreibungen läge darin, dass er die zutretenden Nerven nicht gesehen, Golgi die Kerne nicht erwahnt habe.

S mi r n ow (1888) beschrieb beim Frosche über den Muskelbalken der Lunge "Endknäuel", die dadurch zustande kommen, "dass die myelinhaltige Nervenfaser terminale Zweige abgibt, die als feine, nackte Fäden gewunden verlaufen, Teilungen eingehen und schliesslich in ein Netz feinster variköser Fibrillen übergehen" (S. 259). In den Knäueln fand er eckige Zellen. Diese Endknäuel seien „mit demselben Rechte, wie die Endkolben der Conjunctiva, als Nervenendorgane" (S. 261) aufzufassen.

Cuccati (1888) fand, unabhängig von dieser Mitteilung; dass sich von einem aus markhaltigen und marklosen Fasern bestehenden Netze einzelne Markfasern ablösen, die sich in netzförmige Plättchen „piastretti retiformi ('Taf. XVIII, Fig. 1, 2, 3, 4,5) auflösen. Die Platten, welche den Muskelbalken aufliegen, sind den Fasern entlang fein punktiert und da und dort mit Varikosităten besetzt. Die Nervenfasern enden mit grösseren oder kleineren kugeligen Anschwellungen. 
Wolff (1902) bestätigt die von Smirnow nnd Cuccati aufgefundene Endigungen in der Froschlunge, "vor allem ihre subepitheliale Endigungsweise in einem von $\mathrm{Cuccat}$ i richtig gezeichneten granulärem Belage auf den glatten Muskeln". Es handle sich aber nicht um Knäuel, wie Smirnow angibt, sondern um "ziemlich flach ausgebreitete, der glatten Muskulatur aufliegende Netze" (S. 179). Über die in diesen Netzen vorhandenen Zellen konnte er vorläufig nichts Näheres erbringen.

\section{B. Eigene Untersuchungen.}

Me thoden.

Zur Darstellung der Nervenendigungen wurden hauptsăchlich angewandt: die Vergoldung, die Golgische Methode, die Silberimprägnation, nach $\mathrm{Caja1}$, die Färbung mit Methylenblau, die Behandlung mit Überosmiumsäure und das Sihlersche Verfahren.

Zur Nervenfärbung mit Goldchlorid und Überosmiumsåure verwandte ich folgende mir von Professor K e r schner empfohlene Modifikation:

Vergoldung der Nerven: Die zu untersuchenden Gewebsstücke, deren Durchmesser ungefähr $2 \cdot \mathrm{cm}$ betragen kann, kommen bis zur zarten Braunfärbung in $5 \%$ ige Ameisensiuture, der auf $100 \mathrm{ccm}$ etwa $10 \mathrm{ccm}$ einer $2 \%$ igen Osmiumsäurelösung zugesetzt wird. Nach dem Auswaschen gelangen die Gewebsstücke in eine $1 \%$ ige Goldchloridlösung, worin sie im Dunkeln 2-6 Stunden, bis zur Annahme eines ausgesprochenen gelben Farbentones, verbleiben. Nach dem Abspülen werden die Stücke in 20-25\% ige Ameisensäure übertragen. Darin verbleiben sie vorerst im Dunkeln etwa zwölf Stunden, nach welcher Zeit die Reduktion des Goldchlorids gewöhnlich bedeutend vorgeschritten ist, und dann noch im Tageslichte bis zur vollständigen Redulktion ungefähr 24 Stunden; der Flüssigkeit wird schon hierbei von Zeit zu Zeit Glyzerin zugesetzt. Schliesslich werden die reduzierten Stücke in einer Mischung von gleichen Teilen Glyzerin und Wasser mit Zusatz von 1\% Ameisensäure aufbewahrt; sie können dann nach beliebig langer Zeit untersucht werden.

Ausserdem erhielt ich auch gute Resultate, wenn ich die Gewebsstücke statt mit Gemisch von Osmium- und Ameisensilure mit einem solchen von je fünf Teilen $40 \%$ igen Formalins und konzentrierter Ameisensäure und 100 Teilen Wasser 15-20 Minuten 
lang vorbehandelte, im übrigen aber in gleicher Weise wie bei der eben angeführten Methode verfuhr.

B ehandlung mit Überosmiumsäure. Das bei der Vergoldung angegebene Gemisch von Osmium-Ameisensäure lăsst man im Dunkeln solange einwirken (ungefähr zwei Stunden), bis die markhaltigen Nerven auch in den tieferen Schichten sich schwarz gefärbt zeigen. Die so behandelten Stücke werden dann in das mit Ameisensäure versetzte Glyzerin, die Aufbewahrungsund Untersuchungstlüssigkeit, übertragen und einige Zeit im Dunkeln belassen. Sobald die Flüssigkeit eine braune Farbe angenommen hat, wird sie gewechselt.

Die Golgi-Methode wurde stets in der von Cajal angegebenen Modifikation benutzt. Die Silbermethode von Cajal habe ich in folgender Weise angewandt:

a) Frische Gewebsstücke wurden nach beiläufig 24 stündiger Vorbehandlung mit $96 \%$ igem Alkohol mit oder ohne Zusatz von Ammoniak $(1 \%)$ und darauf folgendem Auswaschen mit destilliertem Wasser gewöhnlich in einer $3 \%$ igen Lösung von Silbernitrat einer Temperatur von cirka $30^{\circ} \mathrm{C}$. bei Lichtabschluss ausgesetzt. Nach 1-3 Tagen waren die Stưcke in der Regel schon gut imprăgniert. Nach sorgfaltigem Auswaschen in destilliertem Wasser wurden sie entweder sofort mit dem Gefriermikrotom in Schnitte zerlegt, die dann in den Entwickler gebracht wurden, oder die Stücke wurden in toto reduziert und je nach der weitern Untersuchungsart behandelt; entweder wurden sie nach dem Auswaschen mit dem Gefriermikrotom in Schnitte zerlegt oder in Celloidin eingebettet, oder endlich bebufs Anfertigung von Isolationspräparaten in die bei der Vergoldung angeführten Vischung von verdünnten Glyzerin und Ameisensäure gebracht. In dieser Flüssigkeit tritt nach Wochen eine Maceration ein, so dass an vielen Objekten ohne weitere Behandlung die Isolation gelingt. Handelt es sich aber um die Zerlegung derberen Gewebes oder ist eine sofortige Untersuchung wünschenswert, dann empfiehlt es sich, die ausgewaschenen reduzierten Stïcke zu erwärmen. Dies kann nach beliebig langem Verweilen in der erwähnten Mischung von Glyzerin-Ameisensäure entweder mehrere Stunden lang bei einer Temperatur von etwa $40^{\circ} \mathrm{C}$. in $25^{\circ} \%$ iger Ameisensäure oder aber $1 / 4-1 / 2$ Minute lang in kochender $25 \%$ iger Ameisensäure erfolgen. Hierdurch werden die Gewebs- 
stücke erweicht und zur Herstellung von Isolationspräparaten geeignet.

Zur Reduktion benützte ich stets den „Agfa-Entwickler der Aktiengesellschaft für Anilin-Fabrikation in Berlin" (Rodinal) in 10-15facher Verdünnung. Dieser Entwickler dringt ungemein rasch ein, so dass für kleinere Stücke eine Einwirkungsdauer von wenigen Minuten genügt und grössere Stücke jedenfalls nach 1/2-2 Stunden vollkommen reduziert sind. Abgesehen von der schnellen und vollkommenen Reduktion wird das Gewebe derart weich, dass man an Quetschpräparaten die Stücke ohne Zeitverlust auf die Güte der Imprägnation prüfen, gegebenenfalls sogar die Untersuchung im Entwickler selbst vornehmen kann.

b) An Material, das vor langerer Zeit konserviert worden war, wurden bei Squatina und Scyllium noch sehr gute Resultate (Fig. 8) erzielt. Die Stücke waren zwei Jahre früber nach $1-2$ stündigem Verweilen in eine Mischung von 10 Teilen Formalin $(40 \%$ ig), 5 Teile Ameisensäure und 100 Teile Wasser in eine Mischung von konzentriertem Glyzerin und $2 \%$ iger Ameisensăure zu gleichen Teilen mit geringem Formalienzusatz ïbertragen und dann in der reinen Mischung aufbewahrt worden. Aus dieser Aufbewahrungsflüssigkeit gelangten sie nach mebrstündigem Auswaschen mit Brunnenwasser auf 12 Stunden in solche mit Zusatz von $1 \%$ Ammoniak, wurden dann für 12 Stunden in $96 \%$ igen Alkohol übertragen und nach abermaligem Auswaschen in destilliertem Wasser in der früher erörterten Wejse mit $3 \%$ iger. Silbernitratlösung behandelt. Nach 24 stündiger Einwirkung der letzteren hatte ich schon gute Resultate zu verzeichnen. Diese Methode, welche nicht so zuverlässig ist, als die für frisches Material benutzte, gelang mir auch ohne Alkoholbehandlung. Auch an Formalin-Material ergab mir die Methode (an motorischen Platten) nach vorhergehender Behandlung der Stücke mit ammoniakalischem $(1 \%) 50 \%$ Alkohol und AlkoholÄther (3:1) gute Resultate.

Farbung mit Metbylenblau: Die durch Bestreichen oder durch Injektion mit 1/10-1\% iger Methylenblaulösung gefärbten Gewebsstücke behandelte ich erfolgreich, wenn eine Untersuchung in konserviertem Zustande wünschenswert erschien, zumeist mit einer gesättigten Lösung von pikrinsaurem Ammoniak, welche, ahnlich dem Verfahren Dogiels mit 1/20-1/10 Volumen 
$2 \%$ iger Osmiumsäure versetzt wurde, eine oder mehrere Stunden lang; hierauf wurden die Stücke in eine Mischung einer gesättigten Lösung von pikrinsaurem Ammoniak und Glyzerin zu gleichen Teilen übertragen. Die Untersuchung erfolgte in dieser Flüssigkeit oder die Präparate wurden in Glyzerin-Gelatine, welche mit pikrinsaurem Ammoniak versetzt wurde, eingeschlossen. Schnitte wurden nötigenfalls nur mit dem Gefriermikrotom angefertigt. Das Bet hesche Verfahren kam seltener zur Anwendung.

Sihlersche Methode: Zur Auffindung der Endkörperchen hat mir diese Methode sehr gute Dienste geleistet, wenn sie auch nur über die gröberen Verhăltnisse (Verteilung der markhaltigen und dickeren marklosen Nerven, Grösse und Gestalt der Körperchen, Verbalten der Scheiden) Aufschluss gibt. Ich änderte die Methode in folgender Weise ab:

Die Gewebsstücke kamen anf $1 / 2-2$ Stunden in das früher angegebene Gemisch von Formalin 10 Teile, Ameisensäure 5 Teile auf 100 Teile Wasser und dann bis zur Färbung, welche beliebig lange hinausgeschoben werden kann, in das angesăuerte Glyzerin. Zur Färbung verwandte ich verschiedene zur Kernfärbung geeignete Hämatoxylinlösungen; diesen wurde eine 'gleiche Menge Glyzerin, welchem 1\% Ameisensäure beigefügt werden kann, zugesetzt; in diesem Gemische verblieben die Stücke etwa 24 Stunden. Aus der Farbe wurden die Objekte in die öfters zu wechselnde Aụfbewahrungs und Untersuchungstlüssigkeit, Glyzerin und Wasser zu gleichen Teilen mit $1 \%$ Alaun, übertragen.

I. Branchiostomen. A mphioxus lanceolatus.

Von Amphioxus stand mir nur Alkoholmaterial zur Verfügung, das ich in Hämalaun durchfärbte und in Glyzerin untersuchte.

Am vorderen Körperende so behandelter Exemplare konnte ich leicht die Hautnerven jener Gegend und die in deren Verlauf vorhandenen Körperchen von $Q$ u atrefages auffinden. Ich sehe aber entgegen den Angaben von Quatrefages (1845), Owsjannikow (1868), Reichert (1870), Krause (1888) und den Zeichnungen von Pouchet (1880, Taf. XXIX, Fig. 7a und b) sowohl die Nervensubstanz, welche vom Zentrum her zu den fraglichen Körperchen herantritt, als auch die den Nerven einhüllende Scheide sich peripheriewärts fortsetzen. Um typische 
Terminalkörperchen im Sinne $\mathrm{K}$ r a u s es kann es sich also keinesfalls handeln; gegen eine „Homologisierung mit Durchgangskörperchen“ spricht der häufige Sitz an Gabelungsstellen und das Verhaiten der Scheide. An meinen Präparaten tritt besonders diese Scheide deutlich hervor, welche erweitert die Hülle der Körperchen bildet, um sich dann wieder gegen den peripherwärts verlaufenden Nerven hin zu verengen; wenn im Körperchell eine T'eilung des Nerven stattfindet, besitzt jeder abgehende Ast seine eigene Scheide. Über die in der Scheide gelegenen Substanz kann ich auch nicht mehr aussagen, als schon Stieda (1873), Langerhans (1876), Rohon (1882) und Fusari (1889) mitgeteilt haben. Dogiel (1903) jedoch hat mittelst Methylenblau festgestellt, dass wenigstens in den meisten Fällen der Inhalt der Nervenscheide den Wert eines Nervenśtämmchens (Fig. 30) und nicht einer Nervenfaser besitzt. Einzeln gelagerte Zellen von $Q u$ atrefages glaubte er auch "endständig und in unmittelbarem Zusammenhang mit Nervenstämmchen" (Fig. 24 b) gesehen zu haben. Hir aber scheint gerade die herangezogene Abbildung nach einem nicht vollkommen gelungenen Methylenblaupräparat angefertigt zu sein; denn die Zelle könnte sich wohl nur in eine einzelne Faser "des Stämmchens" was allerdings eine Deutung der fraglichen Zellen als Ganglienzellen zuliesse - nicht aber in ein ganzes Stämmchen "unmittelbar ${ }^{\text {“ }}$ fortsetzen.

Nach alledem, was wir über die Körperchen von Qu a tre f a ges wissen, können wir also wohl sagen, dass sie keine Terminalkörperchen sind, um aber über den histologischen Wert der in diesen Körperchen gelegenen Zellen ein endgiltiges Urteil zu fällen, sind erneute Untersuchungen mit elektiven Methoden unerlässlich, welche die Beziehung der Einzelfasern der Nervenstämmchen zu diesen Zellen und zur Umgebung klarzulegen hatten.

\section{Il. Pisces.}

a) Selachier.

1. Squaliden.

Die Terminalkörperchen, auf welche sich die folgende Beschreibung bezieht, habe ich bei den fünf von mir untersuchten Haien: Mustelus laevis, Scyllium canicula, Acanthias valgaris, Centrina Salviani und Squatina angelus 
und zwar in den Flossen aufgefunden. Ich konnte sie in allen voll mir untersuchten Flossen nachweisen. Zur Untersuchung gelangten sämtliche Flossen von Scyllium und Squatina; die Brusttlosse, die Schwanzflosse und eine Rückenflosse von Mustelus; die Brustflosse von Acanthias, und die Brust-, Bauch- und Schwanzflosse von Centrina. Nach dem Vorkommen der Terminalkörperchen in sämtlichen Flossen von Scyllium und Squatina dürfte die Anwesenheit ähnlicher Gebilde bei sämtlichen Haien in allen Flossen zu erwarten sein, zumal sie bei Squatina, der Uebergangsform der Haie zu den Rochen, sehr häufig sind, Die Häufigkeit scheint in den einzelnen Flossen ziemlich gleich zu sein.

Der ergiebigste F und ort der Endkörperchen ist das lockere Bindegewebe in der Cimgebung der Radien und Hornfiden, welch letztere auf beiden Seiten der Flosse eine ebenfalls durch lockeres Bindegewebe vom Corium der Haut getrennte Lage bilden. Die Nervenendkörperchen finden sich in diesem und dem zwischen den einzelnen Hornfaden gelegenen Bindegewebe und im grossen Bindegewebslager, das zwischen beiden Hornfädenschichten liegt und sich zwischen die distalen Enden der Radien und die proximalen der Hornfäden hinein fortsetzt. Häufig, namentlich bei Squatina, habe ich sie im Bindegewebe, das die Radien umbüllt, seltener in der Năhe anderer Knorpel des Flossenskelettes gefunden. Meine Bemühungen, die Körperchen auch an andern Körperstellen aufzufinden z. B. in der ausseren Haut, blieben bis jëtzt erfolglos.

Die Endkörper lagern an den genannten Orten entweder in einiger Entfernung von einem grösseren Nervenstämmchen, mit dem sie zumeist nur durch einen längeren oder kürzeren Stiel in Verbindung stehen (Fig. 2, 3,4), oder aber sie liegen, was sehr selten ist, in der Perineuralscheide des Stämmchens.

Die Grösse der Endkörperchen unterliegt beträchtlichen Schwankungen. Die geringste Länge, die ich beobachtet habe, beträgt $50 \mu$, die geringste Breite $30 \mu$, die grösste Länge $720 \mu$, die grösste Breite $250 \mu$. Die Dicke der Körperchen, die gewöhnlich nur etwas geringer als die Breite ist, kann in seltenen Fällen im Verhältnis zu dieser sehr gering sein. Der bessern Übersicht wegen will ich bei den Terminalkörperchen drei Grössen unterscheiden und sie einteilen: in kleine von der Länge bis $125 \mu$ 
und gleicher Breite, in mittlere von der Länge 125--250 $\mu$, und der Breite $40-250 \mu$, endlich in grosse, deren Länge $250 \mu$ und deren Breite $80 \mu$ überschreitet. Es finden sich dann unter 92 untersuchten Endkörpern von Scyllium canicula 31 kleine, 40 mittlere und 25 grosse, wahrend sich eines von $400: 30 \mu$ nicht einreihen lässt; unter 59 Terminalkörperchen von $\mathrm{Sq}$ u a $\mathrm{t}$ in a a ng e lus 32 kleine, 18 mittlere und 1 grosses, während ich eines von mittlerer Länge 170:30 $\mu$ und 7 von grosser Länge (worunter ein Körperchen von $720: 40 \mu$ am meisten auffiel) nicht einfügen kann.

Bezüglich der Gestalt sind die Terminalkörperchen entweder annähernd regelmässig, nämlich kugelig (Figg. 6, 7, 8), oval (Figg. 1, 5), birnförmig oder annähernd konisch (Fig. 10), zylindrisch (Figg. 3,9) oder aber gelappt und in anderer Weise unregelmässig geformt (Fig. 11). Bei der Bestimmung der Gestalt konnte auf den Tiefendurchmesser, durch dessen Verkürzung notwendig eine Abplattung verursacht wird, keine weitere Rücksicht genommen werden, da eine Abplattung durch den Druck des Deckgläschens meist nicht ausgeschlossen werden konnte. Jedoch habe ich, wenn auch selten, entschieden platte Körperchen namentlich zwischen den Hornfäden und Sehnen auffinden können. Von ovalen Körperchen spreche ich, wenn die Länge, als welche ich stets den grösseren Durchmesser des Körperchens ohne Rücksicht auf den Nerveneintritt bezeichne, im Verhaltnis zur Breite auffällig überwiegt, ohne jedoch das Dreifache derselben zu überschreiten; im letzteren Falle zähle ich die Gebilde bereits zu den zylindrischen. Birnförmig oder konisch nenne ich jene Körperchen, welche die Durchmesser ovaler Körperchen besitzen, an der Seite des Nerveneintrittes oder an der entgegengesetzten Seite spitz zulaufen und an dem der Spitze gegenüberliegenden Ende abgerundet sind. Alle übrigen Formen, welche stets eine Mischform zweier oder mehrerer der eben genannten darstellen, zähle ich $z u$ den unregelmässig gestalteten. Häufig wird die unregelmässige Gestalt dadurch verursacht, dass nach irgend einer Seite eine Ausladung des Umrisses erfolgt, oder marklose Teilästchen des eintretenden Nerven, jedes für sich, eigene Knäuel bilden, die miteinander innig zusammenhängen, ähnlich, wie es z. B. Do g i e l (1893) in Taf. XXXIII, Fig. 15 an einem Endlkolben aus der glans penis des Menschen zeichnet; bei Körperchen mit 
mehreren zutretenden Nervenfasern kommen ausserdem verwickelte Formen dadurch zustande, dass die einzelnen markhaltigen Fasern gewissermassen das Bestreben zeigen, mit einem grossen Teil der Äste einen eigenen Knäuel za bilden, während nur ein kleiner Teil derselben die Verbindung der Knauel untereinander vermittelt (Fig. 11). Treten mehrere Nervenfasern in ein Körperchen ein, so bleibt die Form in der Regel dann unbeeinflusst, wenı die Markfasern nahe beieinander zutreten (Figg. 3. 9, 10). Was die Zahl der einzelnen Formen anbelangt, so sind die ovalen weitaus die hâufigsten, indem sie $40 \%$ der 156 daraufhin untersuchten Endkolben ausmachen, während die runden mit $26 \%$, die zylindrischen mit $24 \%$ vertreten sind und der Rest von $10 \%$ gleichmässig den birnförmigen und unregelmässig gestalteten zufällt. Zur Zeit dieser Zusammenstellung bezüglich der Grösse und Gestalt der Endkolben und der Zahl der zutretenden Nerven standen mir 92 Terminalkörperchen von Scyllium, 59 von $\mathrm{Squatin}$ a und fünf von A canthias zu Gebote. Obwohl mil heute wohl dreimal soviel Endkörperchen zur Verfügung stehen, habe ich die seither neu aufgefundenen für die Zählung nicht weiter verwertet, weil sich nach ungefubrer Schiitzung für das Gesamtresultat keine wesentliche Veränderung ergeben laitte. Über die Herkunft der zu den Endkörperchen tretenden Nervenfaseru konnte ich Folgendes ermitteln: Letztere sind in einen grobmaschigen, aus dicken Ästen bestehenden Plexus zurück zu verfolgen, der im Bindegewebe zwischen den letzten Knorpelstücken und der Basis der Hornfäden liegt. Proximalwärts geht dieser Plexus irl die geflechtartig verbundenen Nerven über, von denen auch Muskeläste abgehen, distalwärts löst er sich in ein ebenfalls weitmaschiges, aber aus dünneren Stämmchen zusammengesetztes, zwischen und über den Hornfäden gelegenes Geflecht auf (Fig. 1). Aus diesem entspringen nun ausser den Nerven der Endkolben jene Äste, welche anderweitig im Bindegewebe enden, ferner jene, welche für die Gefüsse, die Placoidschuppen und die Haut der Flossen bestimmt sind.

Von den Markfasern der dickeren und dünneren Stämmchen des Plexus, die von einer ein-bis dreischichtigen Perineuralscheide umgeben sind, lösen sich an Schnürringen einzelne markhaltige Nervenfasern ab (Figg. 3, 4). Einige der sekundären Teiläste gehen nach längerem oder kürzerem Verlauf 
in ein Terminalkörperchen über, andere aber zerfallen dichotomisch (Fig. 3) und trichotomisch (Figg. 2, 5) in tertiäre Äste, die dann sofort oder erst nach weiteren Teilungen in einen Endkolben eintreten.

Die von der letzten Teilungsstelle abgehenden Äste, welche die Terminalkörperchen tragen, sind gewölnlich kürzere oder längere Markfasern (Figg. 3, 4 B), die meistens aus einem einzigen Segment bestehen, oder in vereinzelten Fällen kurze marklose Fasern (Fig. 4 A).

Die Körperchen erhalten entweder je einen (Figg. 6, 7, 8) oder mehrere Nerven (Figg. $2 \mathrm{~A}, 3,4,9,10,11$ ). Im ersten Falle tritt die markhaltige Nervenfaser bei den ovalen Formen haufiger in der Verlängerung der langen Achse ein (längsovale Körperchen), viel seltener senkrecht zu letzterer (querovale Körperchen); an die zylindrischen Gebilde tritt sie an einem Pole, weniger häufig seitlich, mehr oder weniger einem Pole genähert, heran.

Körperchen mit mehr als einem zutretenden Nerven sind verhältnismässig selten und zwar finden sich solche in etwa gleicher Anzahl bei den grossen und kleinen Körperchen. Unter den 156 hierauf untersuchten Endkolben habe ich nur 16 mit mehr als einer Nervenfaser angetroffen und zwar mit zwei Nerven acht bei Scyllium und sechs bei Squatina, mit drei Nerven einen bei $\mathrm{Squ}$ at in a (Fig. 2A), mit fünf Nerven einen bei Scyllium (Fig. 11). Dass die in Mehrzahl zutretenden Nervenfasern von derselben Markfaser abstammen, konnte ich bei 11 Körperchen feststellen. Die Teilung erfolgte bei fünf derselben so, dass sich die Faser an einem Schnürring in zwei markhaltige Äste teilte, bei einem war der eine Teilast markhaltig, der andere marklos (Fig. 10); bei dreien zerfiel eine Markfaser an einem Schnürring in drei Teilaste, wovon zwei in ein Körperchen eintraten, der dritte aber weiterzog (z. B. Fig. 3) und, wenn nicht abgerissen, sich in ein zweites Endkörperchen verfolgen liess. Besondere Beachtung verdient der in Fig. 4 abgebildete Fall: Die von einem dickeren Stämmchen abgegebene Markfaser zerfăllt in zwei beinahe unter rechtem Winkel auseinander weichende Äste. Der eine (I) zerfällt nach längerem Verlaufe in der Höhe von a in zwei tertiäre Teilfasern, eine marklose, die in das Terminalkörperchen $A$ eingeht, und eine markhaltige, welche unweit ihres Ursprungs in die Richtung 
ihrer Stammfaser umbiegt, so dass also die rücklăufige tertiäre Faser hart neben die sekundäre zu liegen kommt, und es den Anschein hat, als ob das Körperchen A von zwei Nerven versorgt würde. An der Teilungsstelle der Stammfaser schliesst sich die rückläufige Faser dem anderen Aste (II) an, um mit diesem das zweite Körperchen $B$ zu bilden. Bei einem anderen Endkolben machte es die Nähe der beiden Fasern sehr wahrscheinlich, dass sie dergleichen Markfaser entstammen, obwohl zentralwärts ihr Zusammenhang nicht mehr nachweisbar war (Fig. 9). Die Körperchen mit drei, beziehungsweise mit fünf mit selbständiger $\mathrm{H}$ e $\mathrm{n}$ I e scher Scheide versehenen Nervenästen zeigen ein ähnliches Verhalten: An einem Endkolben von Squatina (Fig. 2 A) zerfällt eine Markfaser trichotomisch in annähernd gleich lange Äste, welche alle in das Körperchen eintreten. Bei einem Körperchen von Scyllium (Fig. 11) kann man zwei abgerissene Nervenfasern hart nebeneinander verfolgen; die eine (I) teilt sich kurz nach dem Auseinanderweichen der Fasern in zwei markhaltige Teiläste, welche sich beide an dem einen Ende des Körperchens einsenken; die zweite (II) Markfaser läuft gegen das andere Ende des Körperchens, teilt sich in zwei Äste, von denen der eine (1) hier eintritt, der andere (2) durch abermalige Gabelung in zwei weitere Teilaste, einen markhaltigen (a) und einen marklosen (b) zerfällt, welche sich in die seitliche Partie des Körperchens verlieren. Nur bei drei Körperchen mit zwei Nervenfasern, die an verschiedenen Seiten eintreten und auf längere Strecken, weit von einander entfernt, $\mathrm{zu}$ verfolgen sind, konnte ich keinen Anhaltspunkt dafür finden, dass die beiden Fasern aus derselben Markfaser entspringen.

Die Markfasern, welche die Terminalkörperchen tragen, besitzen einen Durchmesser von etwa $5 \mu$ und weisen in Entfernungen von 50 bis $300 \mu$ Ranviersche Schnürringe auf.

Die ovalen Kerne der Schwannschen Scheide sind an einem Segment gewöhnlich in der Mehrzahl vorhanden und besitzen einen meist deutlichen protoplasmatischen Saum.

Die weite Henlescheide ist an der Innentläche mit platten Kernen versehen und geht in die sehr zarte Hülle des Körperchens über.

Die Markscheide wird zumeist kurz vor Eintritt des Nerven ins Körperchen abgestreift; selten erhâlt sie sich 
noch nach dem Eintritt eine ganz kurze Strecke weit, und sehr selten sind grössere Teile einer Windung oder ganze Windungen markhaltig: bei Scylli u m habe ich nur einmal die Markscheide an einer Windung in einer Ausdehnung, welche dem halben Umfange des Körperchens gleichkommt, verfolgen können; bei M ustelus und Squatina habe ich je eilimal zwei bis drei markhaltige Windungen im Körperchen angetroffen.

Die S c h w an n sche Scheide scheint sich nach dem Aufhören der Marlischeide ins Innere des Körperchens fortzusetzen, denn die Kerne, welche den marklosen Nervenfasem anliegen, glichen vollkommen jenen der markhaltigen. Der Protoplasmasaum der zahlreichen Scheidenkerne gewinnt jedoch an den marklosen Fasern eine solche Ausdehnung, dass er deren alleinige Umhüllung zu bilden scheint.

Der zwischen Markfaser und $\mathrm{H}$ en lescher Scheide vorhandene Spalt lässt sich in ein später zu erwähnendes Lückenwerk innerhalb des Körperchens verfolgen.

Im Körperchen zerfält die vor oder nach Eintritt marklos gewordene $\mathrm{Nervenfaser}$ durch wiederholte dichotomische Teilungen in eine Anzahl längerer oder kürzerer glattrandiger Äste, welche schliesslich nach abermaliger Gabelung an Gold- und Methylenblaupräparaten in variköse Faden übergehen (Figg. 7, 10). Diese letzteren stammen von Teilästen verschiedener Ordnung ab; manchmal wird ein Ast schon nach der zweiten Gabelung varikös, während der andere noch weitere Teilungen eingeht und noch in zahlreiche glattrandige Äste zerfällt. Die Gabelungen folgen einander entweder schnell und regelmässig, so dass das Anfangsstück der Verzweigung der „gabeligen Dichotomie“ der Botaniker vollkommen gleicht, oder aber das Geäste ist ein ganz ungleichmässiges, indem die Gabeläste verschiedene Länge aufweisen, wobei es vorkommen kann, dass der eine sehr kurz ist, der andere aber eine ganze Windung im Körperchen beschreibt. Das gesamte Geăste ist mit seinen vielen Windungen und Schlängelungen zu einem Knäuel zusammengeballt. Die dickeren Äste verlaufen hierbei vorwiegend in den inneren Partien des Körperchens, während die dünneren und varikösen Fäden vorzüglich oberflächlich liegen. In der Anordnung der Fasern lässt der Knäuel auch insofern eine gewisse Regelmässigkeit erkennen, als die dickeren Äste zumeist annăhernd parallel in der Langs- 
richtung des Körperchens verlaufen, was namentlich bei ovalen und zylindrischen sehr deutlich hervortritt und ibnen ein längsgestreiftes Aussehen verleiht (Figg. 3, 11). Das Umbiegen der Fasern findet fast regelmässig an den Polen statt, während die Gabelung und das Auseinanderweichen der Teiläste gegen beide Pole in der ganzen Länge des Körperchens erfolgt. Auch an runden Körperchen ziehen die Nervenäste annähernd parallel, der Kugelgestalt entsprechend sind jedoch die Umbiegungen an der ganzen Peripherie anzutreffen.

Die Nervenäste verdünnen sich mit jeder Gabelung; an den Gabelungen selbst tritt eine dreieckige an Goldpräparaten und schwarz imprägnierten Silberpräparaten (nach $\mathrm{Cajal}$ ) meist sehr dunkel gefärbte Verbreiterung auf. Braun imprägnierte Silberpräparate: zeigen diese dreieckige Verbreiterung entweder ganz hell, so dass die Imprägnation im Hauptaste und dessen Teilïsten an dieser Stelle unterbrochen ist, oder aber die Imprägnation der Ästchen lässt sich am Rande der dreieckigen Verbreiterung ohne Unterbrechung in die der Teilästchen verfolgen, so dass nur im Teilungswinkel ein kleines Dreieck heller gefärbt bleibt. Gute Gold- und Silberpräparate zeigen an den dickeren marklosen Fasern eine Differenzierung in zwei Substanzen eine heller gefärbte von fast homogenem Aussehen und eine dunklere, welche bald aus mehreren Körnchenreihen, bald aus Fäserchen zusammengesetzt erscheint, die letzteren liegen innerhalb der bellen Substanz, welche sie einhüllt und zusammenhält. An den Gabelungsstellen scheint sich dieses Bündel von Fibrillen derart zu spalten, dass letztere, ohne eine Teilung zu erfahren, annähernd zur Hälfte in jeden Teilast übergehen. Diese Zusammensetzung der dicken marklosen Fasern ist an Goldpräparaten selten, an braun imprägnierten Silberpräparaten aber fast durchgehends wahrnehmbar. Ich glaube die helle Substanz als Neuroplasma und die dunkle als Neurofibrillen auffassen zu müssen.

Auch an jenen Gabelungsstellen, an denen die varikösen Fäden, wie sie Gold- und Methylenblaupräparate zeigen, ihren Ursprung nehmen, finden sich die oben erwähnten dreieckigen Verbreiterungen. Einen Zerfall der varikösen Fäden, welche bedeutend dünner sind als die glattrandigen, habe ich nicht beobachtet; ich möchte sie daher alle als die Endfäden ansehen. Ihre rundlichen und dunklen Varikositäten lassen sich an gut Archiv f. mikrosk. Anat. Bd. 71. 
imprägnierten, aber nicht ganz tadellos konservierten Präparaten noch in vier bis fünf dunkle Körnchen auflösen. Die dünnen Verbindungstücke der einzelnen Varikositäten nebmen eine gleichdunkle Färbung an. Die varikösen Fasern sehe ich gewöhnlich mit einem Knöpfchen von annähernd gleicher Grösse, wie die Tarikositäten selbst, enden, so dass ich es dahingestellt sein lasse, ob jenes überhaupt das ausserste Faserende darstellt. An Silberpräparaten sind selbst an den dünnsten Fasern keine Varikositäten wahrzunehmen; erstere enden an guten Präparaten, bei welchen die Imprägnation schwarz ausgefallen ist, mit einem grösseren, runden, von einem hellen Hofe umgebenen Knöpfchen. Die Länge dieser knöpfchenförmig endenden Fasern des Silberpräparates und der varikösen Fasern des Goldpräparates macht oft eine in der grössten Auślehnung des Körperchens beschriebene Windung aus, wobei Überkreuzungen mit anderen Fasern häufig vorkommen. Anastomosen zwischen den Endfüden konnten in keinem Falle nachgewiesen werden. Bei der Verschiedenheit der Imprägnation der Endfaden liegt es nahe, in Erwägung zu ziehen, ob die glatten knöpfchenförmig endenden Fäden des Silberpräparates sich mit den varikösen Fäden des Goldpräparates decken, oder ob vielleicht erstere bloss den letzten glattrandigen Fasern des Goldpräparates entsprechen und die knöpfchenförmige Anschwellung mit der letzten dreieckigen Verbreiterung, jener Teilungsstelle, aus welcher die varikösen Fäden hervorgehen, auf gleiche Stufe zu stellen wäre. Wenn ich annähernd gleichgrosse, mit der Silberbeziebungsweise Goldmethode dargestellte Terminalkörperchen vergleiche, so ist die Zahl der glattrandigen und knotigen Windungen des Goldpräparates ungefăhr gleichgross als die sämtlicher glattrandiger Windungen des Silberpräparates, was jedenfalls für die Gleichwertigkeit der als Endfäden erscheinenden, jedoch verschieden gestalteten Faserformen spricht. Ferner ist das Endknöpfchen des Silberpräparates meist zu gross, als dass es einer dreieckigen Verbreiterung entsprechen könnte, und an allen derartigen Präparaten gleichartig rund gestaltet, auch von einem hellen Hofe umgeben; aus alledem dürfte wohl der Schluss zu ziehen sein, dass in diesen Knöpfchen die durch Silbernitrat darstellbare Substanz des Nerven ihr Ende findet. Der Unterschied des Silberbildes vom Goldgebilde, das Fehlen knotiger Verdickungen dürfte, wie ich auch aus dem Vergleiche anderer entsprechend behandelter 
Nervenendigungen schliesse, wohl auf die verschiedene Empfänglichkeit des Neuroplasma für beide Metallsalze zurückzuführen sein.

Das innere Gerüst, welches als Träger der Nervenendverzweigung den ganzen Binnenraum der Endkörperchen von der Nerveneintrittsstelle an durchzieht und sich an die Innenfläche der äusseren Hülle anheftet, gleicht bei Scyllium (Fig. 12) besonders an Goldpräparaten völlig einem zelligen Reticulum; es ist ein von dünneren und dickeren, häufig verzweigten, stellenweise $\mathrm{zu}$ Platten verbreiterten Bändern und von Fäden gebildetes Netzwerk, welches enge längliche und rundliche Maschenrăume einschliesst und kleinere kernlose und grössere kernhaltige Knotenpunkte vom Aussehen sternförmiger Zellkörper aufweist. Die meisten Knoten erscheinen ebenso wie die von ihnen ausgehenden Balken und Fäden feinkörnig. Von der Anwesenheit eines fibrillären Bestandteiles des Gerüstes vermochte ich mich an meinen, allerdings durchgehends mit Săuren behandelten Präparaten nicht zu überzeugen.

In den grösseren vielstrahligen Knoten, welche vor'viegend mit stärkeren Balken zusammenhängen, finden sich innerhalb der körnigen Masse grosse Kerne, über déren Zahl weiter unten berichtet wird; sie erscheinen in der Aufsicht am häufigsten rund, mit einem Durchmesser von ungefähr $10 \mu$, in der Seitenansicht oval; viel spärlicher sind nierenförmige oder stäbchenförmige Kerne. Nicht selten findet man zwei stark genäherte Kerne, welche an den einander zugekehrten Polen abgeplattet, stets aber noch von einer dünnen Schichte fein granulierter Substanz getrennt sind. Die Kerne besitzen eine deutliche Membran, ein gut ausgeprägtes Gerüst und mehrere kleine Kernkörperchen.

In die viel zahlreicheren kleineren, kernlosen Knotenpunkte des Netzes strahlen meist nur wenige dünnere Fäden und Balken ein.

Über das Verhältnis der Nervenfasern zu dem Gerüste geben gelungene Gold- und Silberpräparate Aufschluss, in welchen sich die Nervenfasern durch ihre dunkle Färbung deutlich von dem blassen Reticulum abheben. Die kernhaltigen, häufig zu Paaren vereinten Knotenpunkte des Netzes sind am Übergang der markhaltigen Faser in die marklose, in der Nähe der Teilungswinkel und an den Kreuzungsstellen der marklosen Fasern dichter gelagert. Ein Teil derselben schmiegt sich einer und selbst 
mehreren benachbarten Nervenfasern, an diesen hügelige Erhebungen bildend, dicht an, die Mehrzahl aber liegt in den Zwischenräumen zwischen benachbarten Fasern. Eine entsprechende Lagebeziehung bleibt auch bei den stärkeren und längeren Fortsätzen der beiderlei Knoten, die miteinander durch kürzère Bälkchen in Verbindung stehen, erhalten. So schliessen sich lange Ausläufer der kernhaltigen Verdickungen, welche den Nervenfasern anliegen, diesen allseitig als breite Säume an, während die längeren Fortsätze jener Knoten, welche nicht in unmittelbare Berührung mit den Nervenfasern kommen, die Zwischenräume zwischen den letzteren durchziehen, und hierbei nach allen Seiten Zweigballkchen abgeben. Erst diese letzteren treten, sofern sie sich nicht mit ähnlichen Bälkchen der Nachbarschaft verbinden, an die nächsten Nervenfasern heran und gehen, zumeist vermittels einer dreieckigen Verbreiterung, in die vorerwähnten Säume über. Auch einzelne der kürzeren, unmittelbar von den Knoten selbst ausgehenden Bälkchen setzen sich in ähnlicher Weise mit benachbarten Nervenfäden in Verbindung. Alle diese die Nervenfaseln begleitenden und an sie herantretenden Fortsătze verschmelzen zu einer einheitlichen; die eingeschlossene Faser an Breite übertreffenden, feinkörnigen Hülle. So weit ich seben kannte, ist diese Scheide eine vollständige; optische Querschnitte zeigen nämlich den Achsenzylinder, wenigstens an den dickeren Fasern, in der körnigen Masse meist exzentrisch gelagert, aber von ihr vollkommen umhüllt. Im Bereich der anliegenden kernhaltigen Verdickungen besorgen diese selbst die Umhüllung.

Diese Scheiden werden durch zahlreiche kurze Bälkchen an die aussere Hülle und an die in den Zwischenräumen zwischen den Nervenfasern liegenden Gerüstteile angeheftet und innerhalb der die genannten Bildungen trennenden Maschenrăume in Scbwebe gehalten; die letzteren liessen sich dem Lückenwerk eines Schwammes vergleichen, während das Reticulum samt den darin eingeschlossenen Nervenfasern dem Schwammgerüst entspricht.

Da die Maschenräume des Gerüstes, wie oben erwähnt, mit dem Spaltraume zwischen Schwannscher und Henle scher Scheide zusammenhängen, welch letztere ich stets nur in die Hülle des Körperchens verfolgen konnte, muss ich das Reticulum als modifizierte Fortsetzung der unterhalb der Perineuralscheide befindlichen Hüllen ansehen, vorwiegend der Schwannschen 
Scheide, die an meinen Präparaten allein deutlich nachweisbar ist, und deren Kerne den Gerüstkernen in jeder Richtung gleichen. Für eine sichere Deutung des Gerüstes, welche wohl auch die Lösung der Frage nach dem Wesen der Schwannschen Scheide fördern dürfte, sind noch weitere, mit besonderen Methoden anzustellende Untersuchungen, welche auch die Endoneuralscheide (Fibrillenscheide) eingehend berücksichtigen, sowie Studien über die Entwicklung der in Rede stehenden Endkörperchen erforderlich. Es ist somit auch die Frage nach dem Verhältnis, welches zwischen dem eben besprochenen Gerüste und dem retikulären Gewebe, das Fritsch als innere Scheide des elektrischen Nerven von Malopterurus beschreibt, den Sal aschen Zellen, ferner Smirnows (1895) "sensibler Unterlage" und Dogiels (1898) sternförmigen Zellen in den sensiblen Plexus des Herzens bestehen könnte, noch nicht spruchreif.

Ein auffälliger Unterschied im Aussehen der eben besprochenen Terminalkörperchen von Scyllium und der sonst im wesentlichen gleich gebauten von Squatin a wird durch das Verhaltnis der Kernzahl zur Grösse der Körperchen bedingt, und zwar ist diese Zahl, auf annähernd gleich grosse Körperchen bezogen, bei Squatina ungefăhr 1,5 mal grösser als bei Scyllium. Diese Verschiedenheit dürfte, da, wie namentlich Silberprăparate zeigen, die Körperchen von Squatin a auch mehr Nervenschlingen besitzen als gleichgrosse Endkolben von Scyllium, hauptsächlich darin ibre Erklärung finden, dass die Knăuel bei ersteren dichtergewunden sind (Figg. 8 u. 9). Zur Veranschaulichung dieser Verhältnisse stelle ich je acht nach der Zahl der Kerne geordnete Körperchen beider Gattungen nebeneinander:

Scyllium:

$70: 150 \mu \ldots 12$ Kerne

$150: 90 \% . .19 \%$

$120: 80 " .25 \quad$ " 25

$170: 90 \# \cdot 29 \quad$,

$180: 110 \eta \cdot .35 \quad$ "

$150: 140 n .38$ n

$250: 100 \# .43$,

$500: 120 \% .70$,
Squatina:

$$
60: 60 \mu . .22 \text { Kerne }
$$$$
80: 60 \# .30 \text { \# }
$$$$
130: 70 \% .34 \text { " }
$$$$
230: 75 \% .40 \text { " }
$$$$
110: 60 \text { \#.41 " }
$$$$
130: 80 \ldots 42 \text { " }
$$$$
300: 50, .60 \text { " }
$$$$
450: 50, \cdot 100 \text {, }
$$

Die kernhaltigen Verdickungen des Reticulums sind bei S cy 1 l i u $m$ ausgesprochen sternförmig, bei $S q u$ a t i n a erscheinen 
sie sehr häufig spindelförmig und liegen den Nervenfasern meist eng an; bei Scyllium sind die Anastomosen zwischen den Knotenpunkten sehr zahlreich, während sie bei $S q u a t$ in a viel spärlicher sind. Diese Unterschiede geben namentlich in Gold-, aber auch an Silber-, Osmium- und Hämatoxylinpräparaten den Körperchen ein so eigentümliches Aussehen, dass es dem Geübten leicht fällt, auf den ersten Blick festzustellen, welcher der beiden Gattungen ein Terminalkörperchen angehört. Mustelus, Acanthias und Centrina stehen bezüglich des Gerüstes, namentlich hinsichtlich des Kernreichtums der Endkörperchen $S q u$ a tin a näher als $\mathrm{Scy} l 1 \mathrm{ium}$.

Die sehr zarte, manchmal streifige Hülle, die, wie erwähnt, die Fortsetzung der $\mathrm{Henleschen} \mathrm{Scheide} \mathrm{ist,} \mathrm{schliesst} \mathrm{sich} \mathrm{eng}$ an die Windungen der äussersten vom Gerüste eingescheideten Nerven an und ist mit spärlichen Kernen versehen.

Hier möchte ich noch einer recht bäufigen Beziehung Erwähnung tun, welche die Terminalkörperchen der $\mathrm{Ha}$ ie zu dünnen markhaltigen und marklosen Nervenfasern aufweisen. Diese letzteren finden sich in dünneren und dickeren Nervenstämmchen der früher erwähnten Geflechte und begleiten die zu den Terminalkörperchen verlaufenden Markfasern nach ihrer Ablösung von Stamme oft bis in die Nähe des Körperchens, von welchem sie sich dann zu demselben Stamme zurück oder zu einem andern hin verfolgen lassen; mitunter treten sie an die Terminalkörperchen so nabe heran, dass man bei dichtem Knäuel und ungünstiger' Lagerung nicht mebr entscheiden kann, ob sie sich innerhalb oder ausserhalb des Körperchens befinden. Von einer anderen Stelle solcher Endkolben lassen sich meist gleichgestaltete Nervenfasern weiterverfolgen (Fig. $4 \mathrm{~b}$ u. b), welche meistens $z u$ einem naheliegenden Nervenstämmchen hinziehen; wo dies nicht gelingt, sieht man stets mehr als eine Faser an das Körperchen herantreten. Da ich nie eine Aufsplitterung solcher Fasern im Körperchen gesehen habe, sie aber öfters ungeteilt jenseits des Körperchens weiter verfolgen konnte, scheinen sie längs des Körperchens und seiner Nervenfasern zu ihren schon eingangs erwähnten Verbreitungsbezirken hin zu ziehen.

Die im Vorstehenden angewandte Bezeichnung der eben behandelten Endigungen der Haie als Terminalkörperchen, Endkolben, Nervenkörperchen usw., ist wohl schon durch die vor- 
liegende Beschreibung begründet. Diese Nervenendigungen sind unter die corpusculären Endorgane im Sinne Waldeyers einzureihen und als Terminalkörperchen im ursprünglichen Sinne Krauses aufzufassen. Wie schon in der vorläufigen Mitteilung hervorgehoben wurde, zeigen diese Bildungen mit gewissen Terminalkörperchen der Säuger und des Menschen in Form und Grösse, namentlich aber in der Art der Nervenverästelung grosse Ähnlichkeit. Die Nervenverzweigung der Terminalkörperchen von Haien steht jener der Meissnerschen Körperchen, der Genitalnervenkörperchen, namentlich jedoch jener der kugeligen Endkolben der Conjunctiva und den von Kerschner (1888) zuerst nachgewiesenen marklosen Knäuelbildungen unter den $\mathrm{R}$ a uberschen Sehnenendkolben, welche vielfach als GolgiMazzonische Körperchen bezeichnet werden, sehr nahe. Auch das gelegentliche Hinzutreten von mehreren Nervenfasern, die Art der Astfolge und der Knäuelbildung haben sie mit den genannten Körperchen gemein. Ein Netzwerk, wie es Dogiel bei letzteren beschrieb, konnte ich bei Haien ebensowenig als an guten Silberpräparaten Meissnerscher Körperchen (nach Cajal) auffinden, sondern sah durchwegs nur, freie Endigungen der Nerven. Die dünneren Fasern, welche die Terminalkörperchen der Haie nur als Weg zu ihren Verbreitungsbezirken benützen, dürften wenigstens zum Teil jenen Fasern an die Seite zu stellen sein, welche, wie Dogiel fand, oftmals zwei Terminalkörperchen miteinander in Verbindung setzen oder aus einem Endkolben austreten und anderweitig enden; vielleicht aber gelıört ein 'Teil zu den "sekundiren Endigungen", die nunmehr bei den meisten Terminalkörperchen nachgewiesen sind. Die dem Achsenzylinder zunächst liegende Substanz, das reticuläre Gerüst der Terminalkörperchen der Haie, welches einem verzweigten Innenkolben der bereits bekannten Terminalkörperchen an die Seite gestellt werden muss, ist relativ kernreich und steht in dieser Beziehung dem Innenkolben von Terminalkörperchen niederer Amnioten (Schlangen und Vögel) und der Embryonen der Säuger nahe. Was nun die Hülle betrifft, so ist sie ausserordentlich zart, ähnlich wie dies bei den Kolbenkörperchen der Eidechsen (Merkel, 1880; Krause, 1881) der Fall ist. Auch durch ihre Lagerung an Stellen, welche dem Drucke besonders ausgesetzt sind, zeigen die Terminalkörperchen der Haie mit einigen 
der genannten Endkörperchen eine gewisse Übereinstimmung; besonders entsprechen sie hierin den „Vaterschen Körperchen tiefer Lagerung" $\mathrm{R}$ a ubers und jenen Endkolben, die der genannte Forscher, dann Golgi u. a. in engster Beziehung zu Sehnen antrafen. Die gelegentlich festgestellte Beziehung der Endkörperchen der Haie zu den Hornfäden, liesse sich auch jener an die Seite stellen, welche die Herbstschen Körperchen zu gewissen Federn, so zu den Schwungfedern, den Steuerfedern des Schwanzes (Will), sowie zu den "Tastfedern" (K ü ster), aufweisen.

Die vielen Analogien des Baues zwischen den Terminalkörperchen der Haie und den Endkolben, namentlich denen des Menschen, legen den Gedanken nahe, dass Terminalkörperchen phyletisch ein uralter Besitz seien; allein der Mangel entsprechender Bildungen bei anderen Gruppen der Anamnien, namentlich bei Amphibien, lässt andererseits das Auftreten von Endkörperchen bei Haien eher als eine Konvergenzerscheinung deuten.

Der Sitz der Terminalkörperchen bei Haien scheint mir, wie oben bereits angedeutet, eine Vermutung hinsichtlich der Funktion zu gestatten, welche durch die angeführten, die Lagerung betreffenden Analogien mit solchen Endkörperchen gestiitzt wird, deren Erregung man bereits mit einiger Berechtigung mechanischen Einwirkungen zuschreibt; sie dürften demnach, ehe der Versuch das entscheidende Wort gesprochen, wohl als Organe aufzufassen sein, welche zur Aufnahme von Druckreizen dienen.

\section{Rajiden.}

Bei den untersuchten Rochen, Torpedo marmorata, Raja miraletus und Raja clavata, vermisste ich an jenen Stellen der Flossen, wo bei den Haien die eben beschriebenen Endkolben vorkommen, letztere Endigungsart, konnte daselbst aber anders gestaltete Nervenendapparate auffinden. Zur Untersuchung gelangten die Brust- und Bauchflossen aller drei genannten Rochen und die Rückenflossen von Torpedo, wobei mir in allen untersuchten Flossen der Nachweis solcher Endapparate gelungen ist. Bei ihrem ständigen und reichlichen Auftreten an den genannten Orten dürften weitere Untersuchungen wohl ihr 
Vorkommen in sämtlichen Flossen der genannten Arten, vielleicht auch sämtlicher Rochen geben. Einem eingehenderen Studium wurden nur die Endapparate von Torpedo marmorata unterzogen, welche der folgenden Beschreibung zu Grunde gelegt sind; bei Raja miraletus und Raja clavata habe ich mich von der Anwesenheit der gleichen Endigungen überzeugt.

Die wenigen auffallend dicken, im Osmium- und Goldpräparat sehr dunkel gefärbten Markfasern, welche diese Endigungen versorgen, entstammen einem vorwiegend aus dünneren Fasern bestehenden Nervenplexus, welcher über dem Knorpelskelett der Flossen, namentlich den Radien gelegen ist. Die grösseren Stämmchen des letzteren besitzen eine aus mehreren Blätterm bestehende Perineuralscheide, deren Blätterreichtum in dem Masse abnimmt, als die Stämmchen dünner werden. Die von diesen Nervenstämmchen einzeln abgehenden Markfasern (Fig. 13) zerfallen seltener nach spärlicher, häufiger nach oftmaliger, meist ungleichmisssiger dichotomischer, seltener trichotomischer Teilung in eine kleinere oder grössere Anzahl markhaltiger Endäste, deren jeder eine marklose Verzweigung trägt. An solchen markhaltigen Einzelfasern konnte ich bei deren Verfolgung in die Stämmchen auch innerhalb dieser wiederholt Teilungen auffinden.

Von markhaltigen Endästen habe ich an einer und derselben Stammfaser solche zweiter bis fünfter Ordnung beobachtet. Dadurch, dass die Teiläste nach den verschiedensten Richtungen auseinander streben, ist das Gebiet der Endausbreitung einer Stammfaser ein ausgedehntes. Hauufig greift das Verbreitungsgebiet einer Markfaser auf das einer Nachbarfaser über.

Der Durchmesser der letzten markhaltigen Teilfasern beträgt etwa $4 \mu$, jener der dicksten Stammfaser etwa $10 \mu$. Die zwischen zwei Teilungen gelegenen markhaltigen Stücke besitzen eine Länge von ungefähr $0,3-2,5 \mathrm{~mm}$ und weisen in Entfernungen von ungefähr $0,3-1 \mathrm{~mm}$ Ranviersche Schnürringe auf.

Die an einem Segment in der Mehrzahl vorhandenen Schwannschen Kerne erscheinen in der Flächenansicht von einem schmalen Protoplasmahof umgeben.

An der weiten Henleschen Scheide, die an ihrer Innenfläche platte Kerne besitzt, sind häufig zwei durch einen sehr engen Spalt von einander getrennte Blatter wahrnehmbar. 
Die markhaltigen Endfasern gehen vorerst in eine längere oder kürzere glattrandige, marklose Faser über; an dieser tritt dann eine Gabelung auf, der noch eine zweite und eine dritte folgen kann. Einmal habe ich beobachtet, dass ein sekundärer markloser Gabelast auf eine kurze Strecke weit wieder markhaltig wurde. Die Teiläste gleicher Ordnung weisen verschiedene Dicke und eine Lünge von $50-250 \mu$ auf. Tertiäre Äste der glattrandigen marklosen Fasern erscheinen in der Regel varikös, seltener ist dies schon bei Teilästen der nächst höheren oder nächst niederen Ord̄nung der Fall. Die dickeren variliösen Fasern zerfallen durch meist rasch aufeinander folgende Gabelungen in eine grössere Anzahl durchaus getrennter, zumeist erst nach längerem Verlaufe frei entweder knöpfchenförmig oder spitz endender dünner variköser Fäden (Figg. 14, 15, 16). Die zumeist geradlinig verlaufenden marklosen Äste und Ästchen nehmen nach der Teilung entweder stark genähert einen nahezu parallelen Verlauf oder aber sie wenden sich nach den verschiedensten Richtungen, wobei manchmal einige Fäserchen noch enger benachbart und parallel verlaufen. Im ersten Falle bietet die ganze Verzweigung das Bild eines Pinsels (Fig. 14), im zweiten Falle kommt es nur an den letzten Verzweigungen oder ïberhaupt nicht zur Pinselbildung und die ganze Endigung weist dann eine buschähnliche Gestalt auf.

An den GabeIstellen der marklosen Fasern sowohl der glatten wie der varikösen, finden sich an Goldpräparaten dunkle, kleine dreieckige Verbreiterungen. Die Varikositäten sind durch gleich dunkle, dünne $Z$ wischenstücke miteinander verbunden.

Die marklosen Fasern tragen Kerne, welche in gleicher Flucht mit den Schwannschen Kernen der Markfaser liegen, Ietzteren ähnlich gestaltet sind und auch mit den Gerüstkernen der Terminalkörperchen der Haie in Gestalt und Anordnung grosse Ähnlichkeit aufweisen. Der diesen Kernen zugehörige Plasmasaum lasst sich mitunter in einen homogenen Contour verfolgen, der namentlich lăngs der dickeren marklosen Fasern von diesen mehr oder weniger abstehend, oft auf weitere Strecken beiderseits wahrnehmbar ist; häufiger jedoch scheint er in eine feinkörnige Substanz sich fortzusetzen, die man namentlich den dünneren marklosen Fasern auf weite Strecken aufgelagert findet. An den dünnsten marklosen Fasern treten solche Kerne 
zahlreicher auf und bedingen mit dem ihnen anhaftenden Protoplasma an den dünnen varikösen Fäden spindelige Verdickungen (Fig. 16). Da die Henlesche Scheide, soweit sie nachweisbar ist, gewöhnlich durch einen Spalt von den marklosen Fasern und den eben erwähnten, wohl als Scheiden aufzufassenden Bildungen getrennt ist, muss ich letztere als Fortsetzung der $\mathrm{Sch}$ w an $\mathrm{n}$ schen Scheide ansehen.

Die Henlesche Scheide der zutretenden Nervenfasern ist bei den Büschen und kleineren Pinseln mit stärker divergierenden Fasern mit Sicherheit eine Strecke weit in die marklose Velzweigung hinein zu verfolgen, wo sie einige aufeinanderfolgende Teiläste einzeln einhüllt. Bei den grösseren Pinseln mit stärker genăherten Endfasern erhält man den Eindruck, als bestünde für das ganze Geăst eine gemeinsame Umhüllung. Das endliche Schicksal dieser Scheide, welche distalwärts immer zarter und undeutlicher wird, liess sich nicht feststellen.

Die eben beschriebenen Nervenendigungen der Rochen müssen, so lange bezüglich der Einscheidung, namentlich der Pinselbildungen, ein endgiltiges Urteil aussteht, zu den einfachen freien Endigungen im Sinne W a ldeyer's gezählt und den zahlreichen pinsel- und buschförmigen Endigungen mit varikösen Terminalfasern an die Seite gestellt werden, welche in velschiedenen bindegewebigen Bildungen bei Vertretern aller Wirbeltierklassen, bei A namnie n zuerst in den Rollettschen Nervenschollen der Amphibiensehne von Sachs und Te Gempt, in neuerer.Zeit in der Schwimmblasenwand der Knochenfische von Dein eka, aufgefunden wurden. Es bedingt jedoch die wenigstens teilweise Zusammendrängung der marklosen Teiläste namentlich an den grossen Pinseln (Fig. 14) und deren weit gegen das Ende verfolgbare, anscheinend gemeinsame Umhüllung eine gewisse Annäherung an Terminalkörperchen, zu denen die Endigungen gezählt werden müssten, falls an ihnen eine gemeinsame von der $\mathrm{H}$ e $\mathrm{nleschen}$ Scheide ausgehende, am distalen Ende geschlossene Hülle sicher nachzuweisen wăre. Da ausserdem bei den untersuchten Rochen trotz eifrigen Nachforschens ein jenem der Haie entsprechendes Terminalkörperchen oder eine andere, einem solchen vergleichbare, Endigung nicht aufgefunden werden konnte und die in Rede stehenden Endigungsarten der einander so nahestehenden Unterordnungen den gleichen Sitz haben, wird der 
Gedanke an deren engere Verwandtschaft nahegelegt und die Besprechung der zuletzt beschriebenen Endigung im Rahmen dieser Arbeit gerechtfertigt. Jedenfalls muss vorläufig mit der Möglichkeit gerechnet werden, bei den Selachiern Übergänge zwischen den beiden Endgebilden aufzufinden und die Terminalkörperchen der Haie auf ähnliche Nervenendigungen, wie sie bei Torpedo vorkommen, zurückzufübren.

Beschreibungen von Nervenendigungen bei Rochen, welche die Möglichkeit nicht ausschliessen, dass sie entweder Terminalkörperchen oder Endigungen betreffen, wie ich sie eben von den Rochen beschrieb, liegen von seiten Pansini's und Purvis' vor. Es wäre demnach die Stellung der grossen in der Rückenaponeurose gelegenen "Sehnenendplatten" und der "Golgischen Körperchen": (Sehnenspindeln), welche Pansini (1888) von

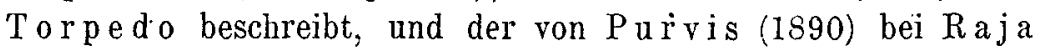
als Terminalkörperchen aufgefassten Bildungen $z \mathfrak{u}$ den von mir aufgeführten Endigungen, insbesondere zu jenen der Rochen, zu erörtern.

In der Rückenaponeurose von Torpedo konnte ich die von $\mathrm{Pansini}$ beschriebenen grossen "Sehnerrendplatten", welche er nach "Grösse, Aussehen und scharfer Abgrenzung vom umliegenden Gewebe" als Terminalkörperchen deutete, nicht auffinden. Da nun die Gebilde, wie Pansini selbst hervorhebt, eine grosse Ähnlichkeit mit motorischen Endplatten besitzen und es in nächster Năhe jenes Fundortes, wie ich mich überzeugt habe, auch grosse motorische Platten gibt, welche binsichtlich der von Pansini aufgeführten Merkmale den Sehnenendplatten (Figg. 11 u. 12), entsprechen, liegt der schon von Perroncito (S. 408) bezüglich $\mathrm{Pansin}$ is Sehnenendplatten von Torpedo geäusserte Verdacht sehr nahe, dass es sich hier um wirkliche motorische Endplatten handle, welche erst durch Verlagerung in năhere Beziehung zum Sehnengewebe geraten sind. Es muss somit die Frage, ob die grossen "Sehnenendplatten" von Tor pedo Terminalkörperchen sind, vorläufig offen bleiben.

Bezüglich der von Pansini aus den Sehnen der Flossen beschriebenen und mit "Golgischen Körperchen" verglichenen Nervenendigung lässt sich nur soviel aussagen, dass es wohl möglich ist, jener Forscher habe den markhaltigen Anteil der von mir bei Torpedo beschriebenen Endapparate gesehen; 
dafür spräche der Fundort in der Flosse und die Dicke der Markfasern (Fig. 13); allerdings habe ich die Endigungen stets nur im lockeren Bindegewebe, nie im Sehnengewebe gefunden.

Die von Purvis als Terminalkörperchen aufgefassten Bildungen haben mit den von mir beschriebenen Terminalkörperchen der Haie nichts gemein, wie ein Blick auf die Zeichnungen von Purvis (Taf. XXXV, Figg. 1-4) und meine Abbildungen besonders bei Berücksichtigung der Vergrösserung zeigt. Die nichts weniger als überzeugenden Zeichnungen legen vielmehr den Verdacht nahe, dass sie überhaupt keine Terminalkörperchen, sondern eingescheidete, am Ende meist geschlängelte, künstlich abgesetzte Nervenfasern wiedergeben, welche kaum über die Markfaser hinaus imprägniert sind. Ähnliche Bilder, wie sie Purvis zeichnet (Figg. 1, 2, 4), habe ich bei Torpedo z. B. in der Rückenmuskulatur öter gesehen. Es handelte sich hier um eine abgerissene, am Ende zusammengeschnurrte dickere markhaltige oder marklose Faser innerhalb eines meist noch aus mehreren dünneren Fasern bestehenden Stämmchens; die Endoneuralscheide war an der Schlängelung beteiligt, während die Perineuralscheide die durch die geschlängelte Faser verdickte Stelle umkleidete, ohne sich selbst an der Windung zu beteiligen. Wenn Purvis solche Kunstprodukte vor sich gehabt hat, dann wäre vielleicht der als aussergewöhnlicher Befund erwähnte spiralig gewundene Faden an der Innen- oder Aussenttäche der Kapsel als eine ebenfalls gewundene dünnere Nervenfaser eines etwa nur aus zwei Fasern bestehenden Stämmchens zu deuten. Der in Fig. 3 abgebildete Fall, wo drei bis vier Nerven in eine gemeinsame Kapsel einmünden, dürfte entweder einen Teil eines dichotomisch oder trichotomisch verzweigten Geästes einer Markfaser oder ein Stück eines aus wenigen Fasern bestehenden Plexus vorstellen. Auch mit den von mir aufgeführten Endigungen der Rochen haben nach dem Gesagten die von Purvis beschriebenen "Endkolben“" nichts zu tun.

\section{b) Knochenfische.}

Da es mir trotz zahlreicher Untersuchungen mit Methylenblau, Goldchlorid, Überosmiumsãure und Silbernitrat (nach $\mathrm{Cajal}$ ) nicht gelungen ist, bei Knochenfischen irgendwelche Endkörperchen aufzufinden, so beschränkt sich meine Aufgabe darauf, die wenigen 
Angaben über Terminalkörperchen, welche zumeist mir unzugängliche Teleostier betreffen, auf ihre Beweiskraft zu prüfen.

Über die "Nervenendkörperchen" von Stomias barbatus ist mir keine andere litteilung als die von $\mathrm{K}$ ölliker (1858) bekannt. Alles, was zur Beurteilung dieser Gebilde von den verschiedenen Autoren herangezogen wurde, ist dem nahe verwandten $\mathrm{Ch}$ a u li od us entnommen. So hat ja Kölliker selbst auf die grosse Ähnlichkeit der "Nervenendkörper" des S to mias mit den von ihm gefundenen "kugelrunden, kleinen Körpern “ von Chauliodus hingewiesen. Le uckart (1865), welcher sowohl bei $\mathrm{Chauliodus}$ als auch bei Stomias "mutmassliche Nebenaugen" auffand, spricht sich gegen die Identität dieser Organe mit den von Kölliker (1853) beschriebenen, den „Nervenknöpfen in Schleimkanälen" vergleichbaren Bildungen aus; Leydig (18ss) aber behauptet die Identität der von Kölliker bei $\mathrm{Chauliodus}$ gefundenen Gebilde mit den von ihm (1879) bei demselben Fische beschriebenen "Hautsinnesorganen ohne Pigment", die wiederum mit den zuerst von Le uckart beschriebenen "Nebenaugen" verwandtschaftlich zusammengehören. Wenn diese Behauptung Leydigs trotz dér verschiedenen Beschreibung zutrifft, so wäre es naheliegend, anzunehmen, dass auch für die "Nervenendkörperchen“ des Stomias eine verwandtschaftliche Beziehung zu den "pigmentierten Nebenaugen" bestehe, da derselbe ja solche ähnlich wie Chauliodus besitzt. In diesem Falle kämen jene Gebilde als Terminalkörperchen überhaupt nicht mehr in Betracht. Krause (1888) sagt aber in einer Anmerkung (S. 146) über die „Endkörperchen“ von Stomias, dass sie einen ganz anderen Charakter hätten als die von Kölliker (1853) beschriebenen Nervenendigungen des $\mathrm{Chauliodus,} \mathrm{welch}$ letztere $\mathrm{Kr}$ a u e mit den "Terminalkörperchen des Amphioxus" in Beziehung $\mathrm{zu}$ bringen sucht. Die Untersuchungen anderer Forscher erbrachten also keine Stütze für die Ansicht, dass die von $\mathrm{Kölliker}$ bei $\mathrm{St}$ omias beschriebenen Gebilde wirklich "Nervenendkörperchen" seien; ebensowenig aber geht dies aus der ursprünglichen Beschreibung Köllikers hervor. Der sehr dïnne zutretende Nerv und der ganze Bau der Gebilde, welche mit jenen des $\mathrm{Chauliodus}$ grosse Ähnlichkeit besitzen, die ihrerseits „ganz vom Bau einfacher Drüsenbläschen mit . . e einer runden Öffnung" sein sollen, sprechen vielmehr dafür, dass es sich 
bei diesen Bildungen entweder um Drüsen, versorgt von sekretorischen Nerven, oder vielleicht um Analoga der Endhügel oder Seitenorgane handelt.

Was nun die "Nervenendkolben" betrifft, die Leydig (1883) bei Lobocheilus beschrieb und zeichnete (Taf. II, Fig. 17), so lassen sich auch diese nicht in die Gruppe der Terminalkörperchen einreihen; denn dass die "Stäbe" in der feinkörnigen Partie gegen den Nerven der Papille biegen, beweist nicht einmal den Zusammenhang jener Gebilde mit Nerven; solange aber dieser nicht nachgewiesen ist, fehlt uns die erste Bedingung, um vom Nervenendkolben zu sprechen. Die aussere Ähnlichkeit dieser Bildungen mit Endkolben höherer Wirbeltiere allein kann uns nicht veránlassen, die fraglichen Gebilde den Terminalkörperchen zuzurechnen. An dem in Fig. 17 abgebildeten "Endkolben" scheint mir aber auch eine äussere Ähnlichkeit mit irgend einem Terminalkörperchen höherer Wirbeltiere zu fehlen.

Gleiches gilt auch von den "Terminalkörperchen-ähnlichen Organen" von Gasterotokeus, welche Brock (1887) beschrieben hat. Er selbst sagt über seine" "Terminalkörperchen": „Die vollkommene Unklarheit, welche über die Beteiligung des nervösen Elementes an dem Aufbau unserer Terminalkörperchen herrscht, dürfte wohl als schlimmste derselben empfunden werden. Nicht nur, dass über den Verlauf und die Endigungsweise der Nerven in den Terminalkörperchen selbst kein Aufschluss zu gewinnen war, es war auch in keinem einzigen Falle überhaupt. die Verbindung eines 'Terminalkörperchen mit einem peripherischen Nerven nachzuweisen." (S. 302.) Der mangelnde Nachweis eines Zusammenhanges dieser Gebilde mit Nerven und das Fehlen einer genaueren Darlegung ihres Baues verbietet vorläufig die Einreibung der genannten Gebilde unter die Terminalkörperchen, um so mehr, als man heute weiss, dass die Querstreifung, die Hauptähnlichkeit, welche der Bau der Körperchen des Gasterotokeus mit dem Bau jener bei höheren Vertebraten darbietet, bei diesen hauptsächlich durch den Verlauf der Nerven bedingt ist, dass also dieses Unterscheidungsmerkmal der Tastkörperchen von den im übrigen ähnlich gebauten Endkolben und Genitalnervenkörperchen an sich die Bezeichnung jener Gebilde als Terminalkörperchen nicht rechtfertigt. 
In der Kopfhaut der Koppe, wo v. Mährenthal in ungewöhnlich hohen, spitz zulaufenden Papillen "Tastkörperchen“ beschrieben hat, konnte ich weder mittels Osmiumsäure, noch mit Hilfe der elektiven Nervenfärbungsmethoden nach Ehrlich, Golgi und Cajal corpusculäre Endorgane, oder andere Bildungen, für welche die von v. Mährenthal gegebene Beschreibung zugetroffen hätte, auffinden. Der Bindegewebskörper der meist breiten, selten schmalen Papillen - jene, welche Endknospen tragen, kommen hier nicht in Betracht - ist sehr oft reichlich von Pigmentzellen durchsetzt, so dass eine Verfolgung der Nerven, die ich aus den breiten Erhebungen öfter ins Epithel eintreten sah, recht schwierig ist; ob aber alle diese Fasern, auch jene der schmalen Papillen, welche relativ kernreich sind, intraepithelial enden, konnte ich nicht entscheiden. Durch Vermittlung Prof. Kerschners gab mir Herr Prof. v. Mährenthal in letzter Zeit freundlichst Gelegenbeit, in seine Präparate Einsicht zu nehmen. An diesen konnte ich mich überzeugen, dass die Spitze meist schmächtiger Bindegewebspapillen, der Beschreibung von Mährenthals entsprechend, einen umschriebenen Haufen von quergestellten, auch säulenartig übereinander gelagerten Kernen enthalt, der samt seiner Zwischensubstanz viel Ähnlichkeit mit den Ihlderschen Körperchen der Vögel, mit den „Merkelschen Tastflecken" bei Reptilien und Amphibien, ja sogar mit Meissnerschen Tastkörperchen besitzt, wie man sie an Präparaten ohne Färbung der marklosen Fasern zu sehen gewohnt ist. Osmiumpräparate zeigen zwischen den Zellen dieser Bildungen dunkle Kontouren, welche v. Mährenthal als Tastscheiben deutet; auch markhaltige Nervenfäserchen können gegen die fraglichen Gebilde hin verfolgt werden.

Den Terminalkörperchen der Haje können die von v. Mährenthal beschriebenen Bildungen also nicht an die Seite gestellt werden, wohl aber gleichen sie in vieler Beziehung den Leydigschen Körperchen des Frosches. Ehe der Verlauf und das Endziel der Nerven der schmächtigen Papillen nicht klar gelegt ist, muss es unentschieden bleiben, ob die Deutung der Tastscheiben v. Mährenthals berechtigt ist und ob das ganze Gebilde den Wert eines Terminalkörperchens besitzt, oder ob die Nerven, ähnlich wie bei den Leydigschen Körperchen und Merkelschen Tastflecken (s. Abschn. B. III., b 1 und 2), nur in einer nachbar- 
lichen Beziehung zu den Zellen der Papillen stehen, mögen sie nun in letzteren oder im Epithel enden.

\section{Amphibien.}

a) Urodelen.

Zur Untersuchung der von Leydig (1876) im Schwanze von Salamandra und Menopoma als Nervenendorgane beschriebenen Gebilde benützte ich Larven von Salamandra atra, da mir solche in allen Grössen zur Verfügung standen; bei den Larven von Salamandra maculosa begnügte ich mich, festzustellen, dass diese Bildungen, was Lage und Bau betrifft, mit denen des Alpensalamanders vollkommen übereinstimmen. Zur Untersuchung gelangten in Paraffinserien die Schwänze 40,32, 22 und $18 \mathrm{~mm}$ langer Larven. Bei der von $40 \mathrm{~mm}$ Länge, die in ihrer Ausbildung einer bereits geborenen entspricht, fand ich an Gebilden, die den Leydigschen entsprechen könnten, nur die Anlagen der Giftdrüsen, die mit einem sehr dünnen, hohlen Stiel mit der Körperoberfläche verbunden sind; ihre Grösse betrug $600: 450 \mu$. Die Drüse der Larve von $32 \mathrm{~mm}$ Lănge erreichte nur die Grösse von'250:220 $\mu$ und stand ebenfalls durch einen kurzen Ausführungsgang mit der Epidermis in Verbindung. Bei der Larve von $22 \mathrm{~mm}$ Lănge waren diese Gebilde in der Grösse von $50: 60 \mu$ noch in breiter Ausdehnung mit dem Epithel verbunden und vollständig über der untersten Coriumschichte gelegen; an der $18 \mathrm{~mm}$ langen Larve stellten sie nur eine $40 \mu$ dicke und $50 \mu$ breite linsenförmige Verdickung der Epidermis vor. Diese Drüsenanlagen der beiden jüngsten Larven entsprechen in ihrer Ausbildung und Lage usw. vollkommen Leydigs (1868) "Organen eines sechsten Sinnes", wie er sie vom Schwanze der Salamanderlarven beschrieb und zeichnete (Taf. II, Fig. 10). Die aus dem Epithelverbande losgelösten und mit der Epidermis nur mehr vermittels eines Ausführungsganges verbundenen Drüsenanlagen erscheinen, wie dies Leydig (1876) von seinen Gebilden angibt, „aus einer gleichmässigen Zellmasse“ zusammengesetzt, in deren Mitte "eine grosse kugelige Partie ... von zarter Beschaffenheit und feiner Körnelung" hervortritt; auch ist das ganze Gebilde von einer "bindegewebigen Kapsel“ umschlossen. Ein wesentlicher Unterschied aber zwischen den von Lieydig (1876) beschriebenen und den von mir eben vorgeführten 
Bildungen besteht darin, dass jener von geschlossenen Kapseln spricht, wăhrend meine Schnittserien keinen $\mathrm{Z}$ weifel darüber bestehen lassen, dass es sich um offene, vermittels eines dünnen Ausführungsganges mit der Epidermis verbundene Bläschen, wie A n cel die Drüsenanlagen der Salamanderlarven beschreibt, und zwar um die Anlagen von Giftdrüsen handelt; A ncel muss ich nach den oben erwähnten Befunden betreffs des ektodermalen Ursprungs dieser Gebilde, trotz der Angaben von Mme. PhisalixPicot, selbstverständlich beipflichten. Leydig untersuchte aber, wie er selbst angibt, die fraglichen Gebilde nur an Isolationspräparaten. Bei Ablösung der Schwanzbaut bleibt ein Teil der Giftdrüsen an der Epidermis haften, ein anderer Teil bleibt im lockeren Bindegewebe des Flossensaumes zurück, in dem ja L e y dig seine "Nervenendorgane" fand; dieser letztere Umstand mag es erklären, dass Leydig von geschlossenen Kapseln sprechen konnte, ferner vielleicht auch, dass er die Zahl der Bläschen bloss auf ein Dutzend schätzte, während ich deren über zwanzig fand. Die von Leydig angegebene Grösse trifft nur für jüngere Larven zu; der Unterschied in der Grösse, der sich nach dessen Angaben für die Organe älterer Larven ergibt, spricht nicht gegen die Identität beider Bildungen, da von Leydig die Länge der untersuchten Larven nicht angeführ't wurde, und die Hautdrüsen ein sehr rasches Wachstum zeigen. Im übrigen stimmen ja Leydigs Angaben mit meinen Befunden überein. Die „bindegewebige Kapsel“ ist also nicht als die Hülle eines Terminalkörperchens, sondern als Anlage der Membrana propria und Muscularis der Drüsen anzusehen. Der zellige Inhalt entspricht den kernhaltigen basalen Abschnitten der Drüsenzellen und die "grössere kugelige Partie ${ }^{\text {in }}$ der Zellmasse dem dem Lumen zugewandten kernlosen, von Sekret erfüllten Teile der Zellkörper. Die zutretenden Nerven sind als sekretorische und, soweit es sich um Nerven der glatten Muskelzellen handelt, als motorische $z u$ deuten.

Kurz, Leydig (1868) hat offenbar die Anlagen der Giftdrüsen am Schwanze der Salamanderlarven, welche anfänglich linsenförmige circumscripte Epithelverdickungen vorstellen, als zu den "Organen eines sechsten Sinnes" gehörige Bildungen angesehen. Die späteren bläschenförmigen, in der Cutis liegenden 
Stadien, wurden von Leydig (1876) als Verwandte gewisser bei höheren Wirbeltieren vorhandener Terminalkörperchen gedeutet.

Le y digs Auffassung, bezüglich der Zusammengehörigkeit der eben behandelten Gebilde von Salam andra und der Nebenaugen von $\mathrm{Chauliodus}$ hat sich insofern als berechtigt erwiesen, als beide Gebilde heute als Drüsen aufgefasst werden müssen.

Leydigs Vergleich seiner Körperchen mit Hyrtls (1865) "vesiculae . . cellulis granulisque repletae" (Fig. 119) bei M e nobranchus und den "Vater-Pacin ischen Körperchen" (S. 120) bei $\mathrm{Cryptobranchus} \mathrm{trifft,} \mathrm{insoweit} \mathrm{Hyl}$ tls Beschreibung einen Schluss gestattet, nur für Menobranchus zu; demnach wären jene mit Zellen und Körnchen erfüllten Bläschen auch Hautdrüsen. Die "Vater-Pacinischen Körperchen" Hyrtls bei Cryptobranchus entziehen sich vorläufig mangels einer genaueren Beschreibung vollkommen der Deutung.

Ma urer unterscheidet bei Cryptobranchus zwei Arten von ,Tastkörperchen": wabre und falsche. Da er mun von den "wahren Tastkörperchen" weiter nichts aussagt, als was im Abschnitt A III. a angeführt wurde, und Tastkörperchen bei Urodelen wenigstens im Sinne Maurers von niemand gesehen wurden, liegt die Vermutung nahe, dass er die Merkelschen "TastHecke" meinte; allein da Maurer ihre Entstehung mit der Ausstossung eines "Hautsinnesorganes" in Zusammenhang bringt, die Tastkörperchen aber dort entstehen 1asst, wo ein Hautsinnesorgan nicht zur Ausbildung kommt, kann man diese Vermutung nicht aufrecht halten.

Es bleibt somit unklar, was Maurer unter den "wahren Tastkörperchen" bei Cryptobranchus versteht. Was aber die "falschen Tastkörperchen" betrifft, so sind sie schon durch Maurers eigene Bezeichnung als Bildungen gekennzeichnet, welche mit Terminalkörperchen nichts $\mathrm{zu}$ tun haben. E's bliebe nur noch die Frage zu erörtern, wie Maurer trotzdem dazu kam, sie mit Tastkörperchen in Zusammenhang zu bringen. Nach den im Absatz A III. a mitgeteilten Sätzen tut er dies offenbar deshalb, weil er die als falsche Tastkörperchen bezeichneten, verhornten Epidermisbezirke von der Umgebung jener Bildungen herleitet, die er für "Hautsinnesorgane" halt. Es hätten somit diese Bildungen die Bestimmung, den durch die Ausstossung eines Hautsinnesorganes gesetzten Defekt in der Epidermis zu decken, 
wären also sozusagen Narben. Abgesehen davon, dass die sensible Natur der in Frage kommenden Hautsinnesorgane nicht erwiesen ist und keine Belege für den genetischen Zusammenhang beider Bildungen vorliegen, wie auch Keibel (1896) hervorhebt, schiene mir selbst in dem Falle als die Bildung jener "Schollen von Hornsubstanz" in der von Ma u rer angenommenen Weise erfolgte, kein genügender Grund für die gewählte Bezeichnung vorzuliegen.

Es entbehrt somit die Aufstellung sowohl "wahrer" als auch "falscher" Tastkörperchen einer genügenden tatsächlichen Grundlage und es verliert demnach auch Maurers Theorie vom genetischen Zusammenhang der Tastkörperchen mit Hautsinnesorganen, in welche übrigens $\mathrm{Ma}$ u rer offenbar auch andersartige Gebilde, ohne in den meisten Fallen ibre nervöse Natur geprüft zu haben, einbezieht, wenigstens soweit sie sich auf die Amphibien stützt, ihren Halt.

\section{b) Anuren.}

1. Leydigsche Körperchen.

Die Zellgruppen in den Papillen des Daumenballens vom Frosch haben die verschiedensten Deutungen erfahren (s. Abschn. A. III. b 1), die ich im Folgenden noch kurz zusammenfasse: Leydig und $\mathrm{Kra}$ use hielten die erwabhnten Bildungen wegen ihrer Ähnlichkeit mit Tastkörperchen und ihrer vermeintlichen Verbindung mit Nerven für Terminalkörperchen. Ciaccio sprach sie für Gruppen von peripheren Ganglienzellen an und sein Schüler Ma z z o n i modifizierte diese Deutung in der Weise, dass er die Zellen für Tastzellen erklärte, an welchen die Nerven mit Knöpfchen enden. Nach Eberth und Merkel gehören die Zellen dem Bindegewebe an und zeigen keine Beziehung zu den Nerven. Eine Mittelstellung nehmen $\mathrm{Eberth}$ und $\mathrm{B} u \mathrm{ng}$ e ein, indem sie zweierlei verschiedenwertige Zellen unterscheiden: die „Endzellen, Terminalzellen" finden sie an den ins Epithel eintretenden Nervenfasern und vermuten in ihnen "Scheidenzellen" der Terminalfasern, sprechen ihnen also doch eine gewisse Beziehung $z u$ den Nervenfasern $z u$; an der anderen Art, den "Papillenzellen", konnten sie nie Nerven finden.

Ich selbst habe die L e y digschen Körperchen an Präparaten, welche in verschiedener Weise fixiert und beliebig gefürbt.worden 
waren, untersucht. Stets fand ich in dè Spitze der Papillen über der Kapillarschlinge mehrere Kerne, welche bald übereinander geschichtet, bald unregelmässig verteilt, den oberen Teil der Papille fast ganz erfüllten. Im ersten Falle liessen sich die zu den einzelnen Kernen gehörigen Zellkörper nicht abgrenzen, im letzteren waren sie gewölnlich von spindel- oder sternförmiger Gestalt. Diese sternförmigen Zellen unterscheiden sich, wie namentlich Osmiumpräparate zeigen, in nichts von den in den obersten Schichten der Cutis gelegenen Zellen, mit denen auch sie durch ihre Fortsätze zusammenhängen. Gelegentlich sind gleichgestaltete Zellen auch seitlich in den Papillen gelegen und zwischen die beiden obgenannten, sich nur durch ihre Lage unterscheidenden Zellennetze eingeschaltet.

Präparate, welche von Objekten stammten, die nach der Cajalschen Silbermethode behandelt, aber vor der Reduktion mit dem Gefriermikrotom geschnitten und erst nachträglich mit Rodinal behandelt worden waren, zeigten gelegentlich in den Papillen und der ganzen Cutis deutlich eine grosse Anzahl von hellen Lücken, die zum grossen 'leil untereinander in Verbindung standen; diese waren an einem T'eil dér Präparate unmittelbar vom umliegenden hellgelben Gewebe begrenzt, an anderen zeigte sich, der Lücke eng anliegend, zwischen ihr und dem umliegenden Gewebe ein schwarzer Grenzsaum. War letzterer vorhanden, sah man ihn in die schwarzen Grenzlinien von Nachbarlücken übergehen, auch dann, wenn eine Verbindung der hellen Lücken nicht sichtbar war. In solchen Präparaten liegen die Kerne den schwarzen Begrenzungslinien von aussen dicht an, während sie dort, wo der schwarze Saum nicht imprägniert ist, in das Lumen hineinzuragen scheinen.

An Präparaten, an welchen ich durch Einstich eine Injektion der Lymphgefässe und Lymphspalten vorgenommen hatte, zeigte die Injektionsmasse ein schwer entwirrbares Bild von injizierten Kanälchen und Lücken, von denen sich zum Teil namentlich in der Papillenspitze Fortsätze durch die Basalmembran hindurch in ein zwischen den Epithelzellen gelegenes injiziertes Netz von Kanälchen, wie es schon von Arnold (1875) und Key und Retzius (1881) beschrieben worden ist, verfolgen liess. Yon diesem Netze drangen kurze seitliche als Ausguss von Kanälchen erscheinende Fortsätze in die Zellen ein, welche in einen den 
Kern umgreifenden Spalt verfolgt werden konnten. Diese den Kern umgebende Lücke - als solche erscheint sie nicht nur an Injektion, sondern auch an Silberpraparaten - dürfte wolll den Saftkanälchen in den Nervenzellen an die Seite zu stellen sein und scheint nach meinen bisherigen Befunden in allen nicht verhornten Zellen geschichteter Pflasterepithelien vorzukommen; wenigstens gelang es mir, sie auch an vielen anderen Stellen der Haut des Frosches und in der Zungenschleimhant des Kaninchens durch Injektion darzustellen.

An Golgi präparaten war in der obersten Schichte der Cutis ein über den Kapillaren gelegenes helles Maschenwerk von grober Körnelung sichtbar, das sich oft bis in die Spitze der Papillen fortsetzte und in ihnen eine periphere Lage einnahm. Es setzte sich aus netzartig verbundenen bandartigen Streifen von wechselnder Breite zusammen, deren Breitseite parallel del Grenze zwischen Epidermis und Cutis eingestellt war. Dass die beschriebene Körnelung kein natürliches Pigment ist, geht schon daraus hervor, dass sie sich dort, wo solches vorkommt, von diesem durch die helle Farbe unterscheidet, und dass der zur einen Hălfte nach Golgi, zur anderen in beliebiger Weise behandelte Daumenballen nur im Golgiprüparat das Maschenwerk zeigt. Die Kerne sah ich diesen grobkörnigen Strängen oft eng anliegend, gerade so, wie sie sich im Silberpräparat zu den hellen Lücken verbalten; in keinem Falle konnte ich mich aber davon überzeugen, dass sie auch innerhalb des Niederschlages, etwa an einer körnchenfreien Stelle, vorbanden seien. Die Form des Maschenwerkes selbst hat mit den untereinander verbundenen Lücken des Silberpräparates grosse Ähnlichkeit und gleicht zum T.eil dem durch Asphaltinjektion dargestellten Netze.

Ausser dem hellbraunen Maschenwerke finde ich, gleich wie Eberth und Bunge, namentlich dort, wo dieses nicht imprăgniert ist, in den Papillen dunkle sternförmige Niederschläge, in Gestalt und Verbindung ganz ähnlich den sternförmigen Zellen im Osmiumpräparat; in dẹ Mitte der imprangnierten Gebilde ist manchmal ein ovaler rötlicher Fleck wahrzunehmen. Ein Teil der Auslăufer dieser sternförmigen Bildungen tritt ins Epithel, ein anderer verliert sich in der Papille oder tritt mit anderen gleichen Gebilden in Verbindung. Wenn solche dunkel imprignierte Fortsătze, was jedoch selten vorkommt, bis zu dem hellen grob- 
körnigen Netz heranreichen, so sehe ich beide Bildungen nicht ineinander übergehen, sondern ohne merklichen Zwischenraum nebeneinander liegen. Ausser diesen beiden Bildungen liessen sich von anderen unregelmässig gestalteten Niederschlägen aus, welche in der Papillenspitze gelegen waren, viele Fortsätze ins Epithel verfolgen, die ganz das Aussehen der vermittels Asphaltinjektion dargestellten feinen Kanälchen zeigten. Im Epithel selbst waren auch Niederschläge vorhanden, die änlich aussahen, wie das als Ausguss feiner Kanälchen erscheinende Asphaltnetz.

Wenn ich nun die Deutung der mit den verschiedenen Methoden dargestellten Bildungen versuche, so stimmen, wie ich schon hervorgehoben, die nach Golgi dargesteliten dunkeln sternförmigen Niederschläge in ihrer Gestalt und Grösse und auch im Verhalten ihrer Ausläufer mit den sternförmigen Zellen der Papillen überein. Der rote Fleck innerhalb dieser schwarzen sternförmigen Gebilde wäre dann wohl als Kern zu deuten, wie es schon Eberth und Bunge getan. Allein, da ausserdem noch Gebilde imprägnier't sind, die mit den injizierten Kanälchen vollkommen übereinstimmen, liegt die Vermutung nahe, dass sich neben zelligen Flementen auch Kantlchen und Hohlräume geschwärzt haben, wobei allerdings die Möglichkeit zu erwăgen wäre, dass die Imprägnation nicht den Inhalt der Kanälchen, sondern eine die letzteren umgebende Substanz betrifft. Zwischen Zellen und Kanälchen besteht also an derartig imprägnierten Golgipräparaten keine scharfe Grenze und die Möglichkeit, dass jene sternförmigen Gebilde zum Teil auch Lücken entsprechen, muss in Betracht gezogen werden.

Weiter drängt sich die Frage auf, in welchem Verhaltnis der dunkle sternförmige Niederschlag zu den hellen, grobkörnig imprägnierten Maschen steht. Da beide Bildungen äusserst selten nebeneinander vorkommen, läge es, zumal ibre Gestalt unter Umständen sehl ähnlich ist, nahe, sie für gleichwertige Gebilde $\mathrm{zu}$ halten, welche, unter anderen Bedingungen imprägniert, nur eine verschiedene Farbe angenommen hatten. Jene wenigen Stellen aber, wo beide Bildungen, die sich wohl berühren, aber nicht decken, nebeneinander vorkommen, lassen ihre Verschiedenartigkeit erkennen. Ziehen wir ferner in Erwägung, dass das grobkörnige Maschenwerk sich in seiner Gestalt und Beziehung zu den Kernen gleich verhält, wie die hellen Lücken des Silberpräparates, sich 
überdies mit einem Teil der mit Asphalt gefüllten Lücken deckt, so lässt sich mit diesen Tatsachen kaum eine andere Deutung in Einklang bringen, als die, dass dieses helle Netz Saftspalten entspricht. Aus der nahen Beziehung dieser Gewebsspalten mögen sie nun in Form des Asphaltnetzes, oder des grobkörnigen nach Golgi dargestellten Maschenwerkes, oder als helle Lücken des Silberpräparates erscheinen - zu den Zellkörpern ergibt sich, dass die Spalten den Zellen und deren Ausläufern entlang sich finden und diesen unmittelbar anliegen.

Die zwischen den grossen Drüsen aufsteigenden Nerven des Daumenballens, die in der obersten Schichte der Cutis ihr Mark verlieren, konnte ich sowohl an Methylenblau- und Golgipräparaten, als auch an Silberpräparaten nach Cajal ins Epithel hinein verfolgen. Nur ein T'eil der Nervenfasern benützt die Papillen, in denen gelegentlich eine Nervenschlinge wahrnehmbar ist, als Weg zum Epithel, wăhrend der andere direkt zwischen den Papillen eintritt; die letzteren Fasern treten annahernd senkrecht ein, biegen über der untersten Schichte der Epithelzellen um und bleiben sich schlängelnd auf längere Strecken in dieser Höhe, indem sie aufstrebende, frei endigende Ästchen in die oberen Schichten abgeben. Die auf dem Wege der Papillen ins Epithel tretenden Nerven zeigen oft auch ein ahnliches Verhalten, wie die ausserhalb derselben eintretenden, meistens aber ziehen sie geradenwegs in die höheren Lagen des Epithels. Nerven, welche in den Papillen selbst ihr Ende gefunden hătten, habe ich nicht gesehen. Die Nervenfasern erscheinen im Golgipräparat oft nicht bloss mit den als Lückenwerk aufzufassenden grobkörnig imprägnierten Maschen und den dunkleren sternförmigen, als imprägnierte Zellen der Papillen gedeuteten Gebilden innig verbunden, sondern sie lassen sich auch von den imprägnierten Kanälchen der Cutis und des Epithels nicht sondern. Wie aber die anderen Methoden zeigen, handelt es sich nicht um eine so innige Verbindung der Nerven mit den sternförmigen Zellen, wie Eberth und Bunge und auch Giacomini (1898) angeben sondern wohl nur um Nachbarschaft selbständiger Gebilde. Der scheinbare Zusammenhang stammt wohl daher, dass in den Spalten zwischen den sternförmigen Zellen und den Nervenfasern, die vielleicht gerade die Saftspalten als Weg zum Epithel benützen, ein Niederschlag erfolgt ist, oder dass die engen Zwischenräume 
deshalb verschwunden sind, weil, wie überhaupt im Golgiprăparat, die Imprägnation der verschiedenen Gebilde über deren Grenzen hinausreicht.

Alle Nervenfasern also, welche ich an Methylenblau- und Silberpräparaten (nach Cajal) gesehen habe, und ich glaube, alle in den Papillen vorhandenen durch diese. Methoden zur Darstellung gebracht zu haben, sind ausser Zusammenhang mit den sternförmigen Zellen. Aber auch Golgipräparate lassen zum Teil eine Abgrenzung von Zellausläufern und Nervenfasern zu; so zeigt z. B. auch Eberths und Bunges (1893) Fig. 4 ein doppeltes System von Ausläufern, von denen die einen durch Zartheit, Verlauf usw. mit meinen eigenen Bildern rein imprägnierter Nervenverzweigungen übereinstimmen, während die breiten, welche mit den als Zellkörper gedeuteten kernhaltigen Knotenpunkten innig zusammenhängen, den Bildern entsprechen, die ich zum Teil als Zellauslăufer, zum Teil als Saftlücken deuten musste. Die Nervenendigungen "mittels besonderer Endzellen“ dürften also wenigstens zum Teil nicht als intraepitheliale Nervenendigungen, sondern als geschwärzte Saftkanälchen, vielleicht auch als Zellfortsätze aufzufassen sein.

Mit den eben erörterten Befunden lässt sich eine Reihe von Beobachtungen früherer Forscher in Einklang bringen; so sind die in den Papillen befindlichen Kerne, ohne als solche erkannt worden zu sein, offenbar schon von Leydig (1856) als "sechs und mehr rundliche Klümpchen" und von Krause (1860) als "Körnchen", welche die Terminalkörperchen ausser dem Nervenglomerulus erkennen lassen, gesehen worden. Bezüglich der Auffassung der fraglichen Gebilde als Zellen, die von Ciaccio stammt, stehen meine Befunde mit den Ergebnissen aller späteren Untersucher im Einklang. Was aber die Deutung der Zellen selbst betrifft, hinsichtlich deren nur zwischen Eberth (1869) und Merkel (1880) eine Übereinstimmung besteht, so kann meine Auffassung als eine Erweiterung jener der beiden Forscher gelten.

Bezüglich des Verhaltens der Nerven, mit Ausnahme ihrer Beziehung zu den „Endzellen“, stimmen meine Ergebnisse im wesentlichen mit jenen von Eberth und Bunge überein, den einzigen Forschern, welche hier eingehend mit einer elektiven Nervenfärbungsmethode gearbeitet haben und deshalb auch bis 
jetzt allein über das Verhalten der marklosen Fasern, um welche es sich hier handelt, Aufschluss geben konnten.

Die Unterschiede zwischen den Ergebnissen früherer Beobachter und den meinen betreffen hauptsächlich die Deutung der sternförmigen Zellen. Die Abbildungen (Figg. XXVIII und XXIX) der letzteren bei Ciaccio, der wobl die genauesten Beobachtungen über deren Gestalt und Yerbindung gemacht hat, entsprechen zwar vollkommen dem von mir beschriebenen Zellnetz; der Auffassung des genannten Forschers aber, welcher in den sternförmigen Zellen Ganglienzellen sehen will, vermag ich nicht beizupflichten, sondern ich halte sie für Bindegewebszellen, welche wenigstens teilweise zu Saftlücken in Beziehung stehen. Das "Geflecht von Nervenfasern", von dem Ciaccio spricht, ist, wenn überhaupt, nur zum geringsten Teil von Nervenfasern gebildet; vielmehr besteht es aus langen Fortsätzen der verästelten Zellen, welch letztere wohl, der Angabe dieses Forscher's gemäss, während der Laichzeit die grösste Ausbildung zeigen, sicherlich aber auch ausser der Laichzeit, in der wärmeren Jahreszeit überhaupt, sternförmig sind.

Eine Unterscheidung der Zellen in „Endzellen" und „Papillenzellen", wie sie Eberth und Bunge vornehmen, kann ich nicht als begründet ansehen; denn es zeigen die „Endzellen“ die gleiche Gestalt und Lage, wie die sternförmigen Zellen in den Papillen und bieten andererseits in ihrer Struktur (vergl. z. B. den Kern in der Abbildung Taf. XI, Fig. $2 \mathrm{E}$ der genannten Forscher) kein einziges charakteristisches Merkmal, das eine Trennung berechtigt erscheinen liesse. Ich muss also beide Zellarten sowohl untereinander als auch mit den über den Kapillaren gelegenen Zellen für gleichwertig halten. Übrigens scheint es mir, wie früher hervorgehoben wurde, fraglich, ob die "Endzellen" in ihrer ganzen Ausdehnung als einheitliche Zellkörper anzusehen sind. Die Möglichkeit, dass die „Endzellen" Scheidezellen der Nervenfasern seien - wofür sie Giacomini, der sie in einer kurzen Bemerkung für Bindegewebszellen erklärt, zu halten scheint glaube ich auch ausschliessen $\mathrm{zu}$ können, da diese, soweit sie nachweisbar sind, erstèren an Grösse weit nachstehen und in meinen Präparaten nie sternförmig erscheinen.

Die Deutungen, welche diese Zellgruppen von seiten Leydigs und Krauses als Terminalkörperchen und von seiten Mazzonis 
als Tastzellengruppe erfahren haben, werden gegenstandslos, weil einerseits für die Auffassung der in den Papillen befindlichen Zellen eine andere, sicherere Grundlage in deren Beziehung zu den Saftlücken gewonnen wurde, andererseits im Verhalten der Nerven weder von Eberth und Bunge, noch von mir etwas gefunden werden konnte, was auf deren Endigung in Terminalkörperchen innerhalb der ohnedies winzigen Papillen schliessen liesse. Bei der engen Auseinanderlagerung der in den Papillen gelegenen Zellen allerdings und der damit hervorgerufenen äusseren Ähnlichkeit mit Tastkörperchen lag wohl der Gedanke nahe, dass die Zellgruppe im Dienste des Tastsinnes stehen könnte, zumal bei den angewandten Methoden eine Klarheit bezüglich des Verhaltens der Nerven nicht erzielt werden konnte. Diese enge Auseinanderlagerung ist kein standiges Merkmal, sondern tritt hauptsächlich zur Winterszeit in den Vordergrund, wăhrend namentlich zur Laichzeit die sternförmigen und bis zu einer Anzahl von 20 oder 30 in einer Papille vermehrten Zellen, locker gefügt erscheinen. Der Vorgang ist (s. Abschn. B III. b 2) der gleiche, wie er sich bei der Umwandlung der , Merkelschen Tastflecken" in die Cutispapillen der "Brunstwarzen" abspielt, und damit ist eine grosse Analogie zwischen diesen Hauterhebungen namentlich des Weibchens und den Papillen des Daumenballens gegeben, die sich auch auf das Verhalten der Nervenfasern selbst bezieht; nur ist deren Zabl in den kleinen Daumenpapillen verhältnismässig grösser als in den grossen Hautwarzen.

\section{Merkelsche Tastflecken.}

Für die nervöse Natur der "Tastflecken" hat sich (vergl. Abschn. A III. b 2) hauptsachlich ihr Entdecker Merkel eingesetzt, der zu ihnen Nerven hinzutreten sah, ohne diese aus den Gebilden hinaus, etwa ins Epithel verfolgen zu können; da er ferner den Zusammenhang der blassen Fasern mit der fraglichen Zellgruppe zu sehen glaubte, fasste er diese als einen in sich abgeschlossenen Tastapparat auf, der . sich im wesentlichen nur durch das Fehlen einer Hülle von gewissen Terminalkörperchen (Grandy schen Körperchen, $\mathrm{V}$ e is s n er schen 'Tastkörperchen) der höheren Wirbeltiere unterscheidet. Diese Auffassung, welche in den Tastflecken sozusagen eine Vorstufe der Terminalkörperchen sieht, erfordert es, die Besprechung auch auf diese Zellgruppe 
auszudehnen, zumal sie Ma urer (1895) geradezu als Tastkörperchen bezeichnet, nachdem sie schon Krause (1881) als den Leydigschen Körperchen im wesentlichen gleichgebaute Bildungen, also auch als Terminalkörperchen angesprochen hatte. M e rkel wendet die Bezeichnung "Tastflecken" nur auf die unter dem Epithel gelegene Zellgruppe, nicht wie Huber und Maurer auf die ganze Hauterhebung an, von welcher ja diese "Tasttlecken" nur den der Cutis angehörigen Teil ausmachen. Der Anschauung Merkels über die Natur dieser Gebilde haben sich Mazzoni, Huber und Maurer angeschlossen. Mazzoni hat den Grundgedanken Merkels, dass die Nervenfasern mit den Zellen unmittelbar zusammenhängen, der damals herrschenden Anschauung angepasst und von einem blossen Kontakt gesprochen. $\mathrm{Huber}$ will es sehr' wahrscheinlich gemacht haben, dass die Nervenfasern an den Zellen einer auf der Höhe der Cutispapille der „Brunstwarze" gelegenen Zellgruppe, welche er für eine Tastzellengruppe Merkels ansieht, enden. Ma u rer endlich spricht sich über die Endigungsweise der Nerven in den Tastflecken nicht aus, sondern gibt nur an, dass man erstere leicht zu den "Tastzellen" hin verfolgen könne.

Die Hauterhebungen von Rana temporaria, in welchen die M e rke l schen Tasttlecken vorkommen, zeigen, wie ich finde, ein sehr verschiedenes Aussehen. An der Fusssohle des Männchens sind sie klein und setzen sich aus einer umschriebenen Verdickung der Epidermis und einer Gruppe von wenigen platten Zellen der Cutis zusammen; ein solcher Zellbaufen bedingt, wie $\mathrm{Merkel}$ hervorhebt, entweder keine Niveauverănderung der Cutis, oder aber, er wölbt diese papillenartig vor. Am Seitenrande des Fusses sind diese Gebilde beim Männchen im allgemeinen gleich gebaut aber grösser, die Zellgruppe ist aus einer grösseren Anzahl von Elementen zusammengesetzt. Beim Weibchen (ich untersuchte solche kurze Zeit vor der Laichzeit) sind die kleinsten der dort vorkommenden Hautwarzen und auch der darin gelegene Zellhaufen grösser als beim Männchen und im allgemeinen so gebaut, wie dies Merkel beschreibt und in Taf. IX, Figg. 5 u. 6 abbildet. Solche Hauterhebungen sind nun mit den grössten, welche in ihrem Baue mit den von $\mathrm{Huber}$ beschriebenen "Brunstwarzen" übereinstimmen, durch alle Übergänge verbunden. Die platten, übereinander geschichteten Zellen, wie sie Merkel 
als Bestandteile der Tastflecken beschreibt, sind an den grösseren Hauterhebungen durch grössere Zwischenräume voneinander getrennt, als es an den kleineren der Fall ist und erscheinen im Flachschnitt ausgesprochen sternförmig; an den grössten Erhebungen endlich findet sich zwischen den Zellen reichliches Gewebe von fibrillärer Struktur. Diese 'Tatsachen, wie auch $\mathrm{Hubers}$ Angaben, dass nach der Laichzeit die Warzen niedriger werden und die Cutispapille sich verflacht, lassen es ausser Zweifel, dass aus den Hautwarzen, welche "Tastflecken" enthalten, zur Laichzeit durch Vergrösserung und Umbildung jener zellreichen Erhebungen die Papillen der „Brunstwarzen" hervorgehen. Demzufolge sind nicht, wie $\mathrm{Huber}$ meint, nur die namentlich an der Spitze der Papillen gelegenen, sondern alle dort befindlichen Zellen dér Brunstwarzen der "Tastzellengruppe" Merkels gleichzustellen. Genauere Angaben darüber, wie diese Ausbildung im Einzelnen erfolgt, wie sie sich za den verschiedenen Jahreszeiten verhalt und ob auch die kleinen Hauterhebungen des Männchens eine ähnliche Umwandlung erfahren, wie jene des Weibchens, kann ich vorläufig nicht beibringen; auch gehörten sie nicht in den Rahmen vorliegender Unitersuchung. Eine Angabe, ob Merkel die von ihm beschriebenen und gezeichneten Gebilde bei Männchen oder Weibchen von Rana esculenta gefunden hat, liegt nicht vor. Vielleicht ist bei dieser Art eine solche Unterscheidung auch nicht notwendig, da dort, wie es scheint, die Warzen nicht zu bedeutender Höhe gelangen; wenigstens haben Huber und Swirski (1900) die grösseren Hauterhebungen als eine Eigentümlichkeit des Weibchens von Rana temporaria bezeichnet. Der Umstand aber, dass die von Merkel beschriebenen Hautwarzen der Rana esculenta mit den kleineren von $R$ an a temporaria übereinstimmen und letztere sich als kleinere Form oder als Vorstufe der "Brunstwarzen" erweisen, welch letztere in ihrer Verteilung mit den von Merkel beschriebenen Erhebungen der Haut vollkommen übereinstimmen, lässt es trotz der Grössenverschiedenheit wohl zweifellos erscheinen, dass wir es da und dort mit gleichwertigen Gebilden zu tun haben.

An den "Tastflecken“ und an den Cutispapillen der "Brunstwarzen", welche also offenbar gleichwertige Bildungen vorstellen, konnte ich in Goldpräparaten und noch besser in Silberpräparaten nach Cajal Nervenfasern zwischen den Zellen hindurch zumeist 
bis an die Epidermis verfolgen, öfters auch in diese hineintreten sehen. Mit der Bestätigung des Vorhandenseins von Nervenfasern in den "Tastflecken" wird zwar der gegen ihre nervöse Natur vorgebrachte Einwand von $\mathrm{Eberth}$ und Bunge, dass an sie niemals Nerven herantreten, hinfällig. Allein die Beziehung der Nerven zu den Zellen der Tastflecken erwies sich in meinen Präparaten entgegen der Ansicht $\mathrm{Merkels}$ nur als eine nachbarliche. Der Nervenreichtum dieser Hauterhebungen ist allerdings nicht grösser als der anderer Hautpartien und berechtigt deshalb nicht, den ersteren eine besondere Bedeutung zuzuschreiben, etwa die von Wollustorganen, wie $\mathrm{Huber}$ meinte.

Alle anderen Beobachtungen Merkels über diese Gebilde kann ich nur bestätigen. Was diese einzige allerdings für die vorliegende Frage wesentliche Differenz zwischen Merkels und meinen Ergebnissen betrifft, so musste ja diesem Forscher bei den von ihm mit Erfolg angewandten Untersuchungsmethoden - die Goldmethode hat ihm keine Resultate ergeben - das Durchtreten der in der Zellgruppe sich wiederholt teilenden Nerven durch erstere und deren intraepitheliale Endigung bei der Feinheit der Fasern entgehen. Gegenüber $\mathrm{Huber}$ muss ich bemerken, dass ich in der Papille der "Brunstwarzen" in keinem einzigen Falle habe Ganglienzellen wahrnehmen können und dass von Kernen, die ich mit Nervenfasern in Verbindung sah, nur solche der Schwann schen Scheide vorlagen. Nach den Abbildungen $\mathrm{Hubers}$ scheint es mir wahrscheinlich, dass er sternförmige Bindegewebszellen für Ganglienzellen angesehen hat; die vermeintlichen von diesen Zellen ins Epithel abgehenden Nervenfasern fallen wohl mit Fortsätzen der sternförmigen Zellen zusammen, die, zum Epithel ziehend, wie im Daumenballen des Frosches mit Saftkanälchen in Beziehung stehen dürften. An allen "Brunstwarzen", die ich untersucht habe, sah ich im Gegensatz zu $\mathrm{Huber}$ und in Übereinstimmung mit Leydig das Epithel 4 bis 5 Mal höher als an anderen Stellen der Haut.

3. Untersuchungen über andere, Terminalkörperchen" bei Anuren.

Das Vorkommen von Vater-Pacinischen Körperchen im Gekröse des Frosches, von dem Will berichtet, und von Endkolben in der Conjunktiva von Rana, die Helfreich ein- 
mal gesehen zu haben glaubt, hat von keiner Seite eine Bestätigung erfahren. Auch die von Sachs beschriebenen und gezeichneten "Sehnenendkolben" konnten Te Gempt u. a. nicht wiederfinden. Mir war es trotz vielfacher Untersuchungen gleichfalls nicht möglich, die drei eben erwähnten angeblichen Terminalkörperchen aufzufinden.

An den von $L o ̈ w e ~ a n g e g e b e n e n$ Orten vermochte ich ebensowenig als Kerschner Nervenendorgane, welche auf die von ersterem beschriebenen "Gelenknervenkörperchen" bezogen werden könnten, darzustellen.

Die von Smirnow (1888) aus der Froschlunge beschriebenen und den Endkolben der Conjunctiva an die Seite gestellten "Endknäuel" hat Wolff, der sich der Beschreibung Cuccatis angeschlossen hat, Smirnow s Vergleich entgegen als „ziemlich flach ausgebreitete der Muskulatur aufliegende Netze" gekennzeichnet. Auch meine Präparate zeigten die „piastretti retiformi" Cuccatis in der von diesem Forscher gezeichneten Gestalt, wenn ich mich auch des Eindruckes nicht erwehren konnte, dass es sich vielleicht nur um eine unvollkommen gefärbte Endigung handle, deren Terminalfasern möglicherweise in dem oft recht hohen Epithel der Froschlunge ihr Ende finden.

\section{Literaturverzeichnis.}

Ancel, P.: Recherches sur le développement des glandes cutanées de la salamandre terrestre. C. R. Soc. biol. Paris, Bd. LII, S. 959-961. 1900.

Derselbe: A propos de l'origine des glandes cutanées de la salamandre. Ebenda, Bd. LII, S. 1059-1060. 1900.

Derselbe: Étude du développement des glandes de la peau des batraciens et en particulier de la salamandre terrestre. Arch. biol., Bd. XVIII, S. 257-289. 1901.

Arnold, J.: Über die Kittsubstanz der Epithelien (Anatomischer Teil). Virchows Arch., Bd. LXIV, S. 203-243. 1875.

B r o ck, J.: Über Terminalkörperchen ähnliche Organe in der Haut von Knochenfischen. Intern. Monatsschr. Anat. u. Phys., Bd. IV, S. 301-311. 1887.

Bunge, R.: Die Nervenendigungen in der Froschhaut. Hallenser Diss. Guben 1892.

Cia c cio, G. V.: Intorno alla minuta fabbrica della pelle della rana esculenta. Palermo 1867. 
Cuccati, G.: Sopra il distribuimento e la terminazione delle fibre nervee nei pulmoni della rana temporaria. Intern. Monatsschr. Anat. u. Phys., Bd. V, S. 194-203. 1888.

Deineka, D.: Zur Frage über den Bau der Schwimmblase. Zeitschr. Zool., Bd. 78, S. 149-164. 1904.

D o g i e l, A. S.: Die Nervenendigungen in M e is s ne r schen. Tastkörperchen. Intern. Monatsschr. Anat. u. Phys., Bd. IX, S. 76-8う̌. 1891.

Derselbe: Die Nervenendigungen in der Haut der äusseren Genitalorgane des Menschen. Arch. mikr. Anat., Bd. XLI, S. 585-612. 1893.

Derselbe: Die Nervenendigungen im Lidrande und der Conjunctiva palpebr. des Menschen. Arch. mikr. Anat., Bd. XLIV, S. 15-25. 1895.

Derselbe: Die sensiblen Nervenendigungen im Herzen und in den Blutgefässen der Säugetiere. Arch. mikr. Anat., Bd. LII, S. 44-70. 1898.

Derselbe: Die Nervenendigungen im Bauchfell, in den Sehnen, den Muskelspindeln und dem Centrum tendineum des Diaphragmas beim Menschen und bej' Säugetieren. Arch. mikr. Anat., Bd. LIX, S. 1-31. 1902.

Derselbe: Das peripherische Nervensystem des Amphioxus. Anat. Hefte, Bd. XXI, S. 145-213. 1903.

$\mathrm{E} b$ e $\mathrm{t} \mathrm{h}$, C. J.: Untersuchungen zur normalen und pathologischen Anatomie der Froschhaut. Leipzig 1869.

Derselbe und Bunge, R.: Die Endigungen der Nerven in der Haut des Frosches. Anat. Hefte, Bd. I, S. 173-203. 1893.

Ecker, A. u.Wiedersheim, R.: Anatomie des Frosches. Neu bearbeitet von Dr. E. G a u p p, 2. Aufl., VI. Abt. Braunschweig 1904.

Frits ch, G.: Die elektrischen Fische. 1. Abt.: Malopterurus electricus. Leipzig 1887.

Fusari, R.: Beiträge zum Studium des peripheren Nervensystems von Amphioxus lanceolatus. Intern. Monatsschr. Anat. u. Phys., Bd. VI, S. $120-140.1889$.

Gi a comini, E.: Sulla terminazioni nervose nella pelle delle dita di Spelerpes (Geotriton) fuscus e di Hyla arborea. Atti R. Accad. fisiocritici Siena, Ser. 4, Vol. 10, 29 Jan. S. A. 1898.

Golgi, C.: Ontersuchungen über den feineren Bau des zentralen und peripherischen Nervensystems (X. Über die Nerven der Sehnen des Menschen und anderer Wirbeltiere und über ein neues musculotendinöses Organ, S. 203-216). Übers. von Dr. R. Teuscher. Jena 1894.

Helfreich, F.: Über die Nerven der Conjunctiva und Sclera. Würzburg 1870.

Hensche, A.: Über die Drüsen und glatten Muskeln in der Haut von Rana temporaria. Zeitschr. wiss. Zool., Bd. VII, S. 273-282. 1856.

$\mathrm{H}$ u b e r, O.: Über Brunstwarzen bei Rana temporaria L. Zeitschr. wiss. Zool., Bd. XLV, S. 664-668. 1887.

Hyrtl, J.: Cryptobranchus Japonicus. Wien 1865.

Keibel, Fr: Ontogenie und Phylogenie von Haar und Feder. Ergebn. Anat. Entw.-Gesch., Bd. V, S. 619-719. 1896.

Kerschner, L.: Beitrag zur Kenntnis der sensiblen Endorgane. Anat. Anz., Bd. III, S. 288-296. 1888. 
Key, A. u. Retzi us, G.: Studien in der Anatomie des Nervensystems und des Bindegewebes. II. Stockholm 1876.

Dieselben: Zur Kenntnis der Saftbahnen in der Haut des Menschen. Biol. Unters., S. 105-107. 1881.

Kölliker, A.: In Gegenbauer, Kölliker und Müller, Bericht über einige im Herbst 18502 in Messina angestellte vergleichendanatomische Untersuchungen. Zeitschr. wiss. Zool., Bd. IV, S. 299-370. 1853.

Derselbe: Nervenkörperchen in der Haut von $S t$ omias barbatus. Verh. Phys.-med. Ges. Würzburg, Bd. VIII, S. 28-31. 1858.

Derselbe: Handbuch der Gewebelehre des Menschen, 6. Aufl., I., Bd. 1. Leipzig 1889.

Kra u s e, W.: Über Nervenendigungen. Zeitschr. ration. Med., 3. R., Bd. V, S. $28-43.1858$.

Derselbe: Die terminalen Körperchen der einfach sensibeln Nerven. Hannover 1860 .

Derselbe: Anatomische Untersuchungen. II. Die Nervenendigungen beim Frosch. S. 49-62. Hannover 1861 .

Derselbe: Handbuch der menschlichen Anatomie. I. Allgemeine und mikroskopische Anatomie. Hannover 1876.

Derselbe: Die Nervenendigungen innerhalb der Terminalkörperchen. Arch. mikr. Anat., Bd. XIX, S. 53-136. 1881.

Derselbe: Handbuch der menschlichen Anatomie. Nachträge zur allgemeinen und mikroskopischen Anatomie. Hannover 1881.

Derselbe: Nervenendigung in der äusseren Haut und den Schleimhäuten. III. Nervenendigungen bei Anamnioten. Biol. Zentralbl., Bd. IV, S. 210-211. 1885.

Derselbe: Die Retina der Fische. Intern. Monatsschr. Anat. u. Phys., Bd. V, S. $132-148.1888$.

Derselbe: Die Entwicklung der Haut und ihrer Nebenorgane. Hertwigs Handb. d. vergl. u. exper. Entwicklungsg. d. Wirbeltiere, 6. -8. Lief., S. 253-348. 1903.

$\mathrm{K}$ üster, E.: Die Innervation und Entwicklung der Tastfeder. Morphol. Jahrb., Bd. 34, S. 126-148. 1905.

L ang e r, C.: Über das Lymphgefässsystem des Frosches. Sitz.-Ber. Akad. Wiss. Wien, math.-nat. K1., Bd. LV, S. 593-636. 1867.

Langerhans, P.: Zur Anatomie der Amphioxus lanceolatus. Arch. mikr. Anat., Bd. XII, S. 290-348. 1876.

L e u c kart R. und $\mathbf{P}$ agenstecher, A.: Untersuchungen über niedere Seetiere. Amphioxus lanceolatus, Arch. Anat. u. Phys., S. 558-569. 1858.

乙euckart R.: Über mutmassliche Nebenaugen bei einem Fische (Chauliodus Sloani). Amtl. Ber. Vers. deutsch. Naturf. u. Aerzte in Giessen 1864, S. 153-155. Giessen 1865.

Leydig, Fr.: Über Tastkörperchen urd Muskelstruktur. Arch. Anat. u: Phys., S. $150-159.1856$.

Derselbe: Übe die Organe eines sechsten Sinnes. Verh. Leopoldino-Carolin. Akad., Bd. XXXIV. 1868.

Archiv f. mikrosk. Anat. Bd. 71. 
Derselbe: Zur Kenntnis der Sinnesorgane der Schlangen. Arch. mikr. Anat., Bd. VIII, S. 317-357. 1872.

Derselbe: Über die allgemeine Bedeckung der Amphibien. Arch. mikr. Anat., Bd. XII, S. 119-242. 1876.

Derselbe: Über die Schwanzflosse, Tastkörperchen und Endorgane der Nerven bei Batrachiern. Ebenda, S. 513-527. 1876.

Derselbe: Nebenaugen von Chauliodus. Arch. Anat. u. Phys., Anat. Abt., s. $365-382.1879$.

Derselbe: Die augenähnlichen Organe der Fische. Bonn 1881.

Derselbe: Untersuchungen zur Anatomie und Histologie der Tiere. Bonn 1883.

Derselbe: Nervenendkörperchen in der Haut der Fische. Zool. Anz., Bd. XI. Nr. 270, S. 40-44. 1888.

Derselbe: Integument brünstiger Fische und Amphibien. Biol. Zentralbl., Bd. XII, S. 205-221. 1892.

Loewe, L.: Über eine eigentümliche Art von Gelenknervenkörperchen beim Frosch. Arch. mikr. Anat., Bd. XVI, S. 615-618. 1879.

v. Maehrenthal, F. C.: Tastkörperchen in der. Haut von Cottus Gobio. Verh. deutsch. zool. Ges., S. 138-139. 1892.

Marcusen, M. J.: Sur l'anatomie et l'histologie du Branchiostoma lumbricum. C. R. Acad. sc. Paris, Bd. LVIII, S. 479-483. Bd. LIX, S. 89-90. 1864.

Ma a rer, Fr.: Die Epidermis und ihre Abkömmlinge. Leipzig 1895.

Mazzoni, V.: Della terminazione dei nervi nella pelle della rana rubra. Mem. R. Accad. sc. Istit. di Bologna. Ser. IV, Bd. VIII, S. 271-282. 1887.

Merkel, Fr.: Über die Endigungen der sensiblen Nerven in der Haut der Wirbeltiere. Rostock 1880.

Derselbe: Bemerkungen zu Herrn Krauses Aufsatz über „die Nervenendigungen innerhalb der terminalen Körperchen". Arch. mikr. Anat., Bd. XIX, S. 523-527. 1881.

Mönckeberg, G. und Bethe, A.: Die Degeneration der markhaltigen Nervenfasern der Wirbeltiere unter hauptsächlicher Berücksichtigung des Verhaltens der Primitivfibrillen. Arch. mikr. Anat., Bd. LIV,

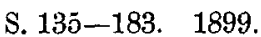

Owsjannikow, Ph.: Über das Zentralnervensystem des Amphioxus lanceolatus. Bull. Acad. sc. St. Petersburg, Bd. XII, S. 287-302. 1868.

Pansini, S.: Delle terminazioni dei nervi sui tendini dei vertebrati. Boll. Soc. Nat. di Napoli, Ser. I, Bd. II, S. 135-160. 1888.

Perroncito, A.: Etudes ultérieures sur la terminaison des nerfs dans les muscles à fibres striées. Arch. ital. Biol., Bd. XXXVIII, S. 393-412. 1902.

Phisalix-Picot, C.: Recherches embryologiques, histologique et physiologiques sur la glandes à-venin de la salamandre terrestre. Thèse. Paris 1900.

Dieselbe: Origine et développement des glandes à venin de la salamandre terrestre. C. R. Soc. biol. Paris, Bd. LII, S. 479-481. 1900. 
Dieselbe: Remarques sur la note précédente. Bd. LII, S. 1060-1061. 1900. Ebenda.

Pouchet, G.: On the Laminar Tissue of Amphioxus. Quart. Journ. micr. Sc., Bd. XX, S. 421-430. 1880.

Purvis, G. C.: Notes on certain terminal organs resembling touch-corpuscles or endbulbs in connective-tissue of the scate (Raja clavata). Quart. Journ. micr. Sc., Bd. XXX, S. 515-518. 1890.

Quatrefrages, M. A.: Mémoire sur le système nerveux et sur l'histologie du Branchiostome ou Amphioxus. Ann. des sc. nat. III. Ser., Zool.: Bd. IV, S. 197-248. 1845.

Rauber, A.: Untersuchungen über das Vorkommen und die Bedeutung der Vater'schen Körperchen. München 1867.

Derselbe: Über die Endigung sensibler Nerven in Muskel und Sehne. Stuttgart 1882 .

Reichert, C. B.: Zur Anatomie des Branchiostoma lumbricum. Arch. Anat. u. Phys., S. 755-758. 1870.

Retzius, G.: Über die Endigungsweise der Nerven in den Genitalnervenkörperchen der Kanixıchen. Intern. Monatsschr. Anat. u. Phys., Bd. VII, S. 323-333. 1890.

Rohon: J. O.: Untersuchungen über Amphioxus lanceolatus. Denkschr. Akad. Wiss. Wien, math.-nat. Kl., Bd. XLV, 2. Abt., S. 1-64. 1882.

Rollett, A.: Über einen Nervenplexus und Nervenendigungen in einer Sehne. Sitz.-Ber. Akad. Wiss. math.-nat. Kl., Bd. 73, 3. Abt., S. 32-53. 1876.

S a ch s, C.: Die Nerven der Sehne. Arch. Anat. u. Phys., S. 402-416. 1875.

S a la, L.: Contribution à la connaissance de la structure des nerfs périphériques. Arch. ital. Biol., Bd. XXIV, S. 387-393. 1895.

$\mathrm{S}$ ch u Itze, M.: Die kolbenförmigen Gebilde in der Haut von Petromyzon und ihr Verhalten im polarisierten Lichte. Arch. Anat. u. Phys., S. 228-247 und 281-303. 1861.

S c hw albe, G.: Lehrbuch der Anatomie der Sinnesorgane. Erlangen 1887.

Smirnow, A.: Ü̉ber Nervenknäuel in der Froschlunge. Anat. Anz., III. Jahrg., Nr. 9, S. 258-261. 1888.

Derselbe: Über die sensiblen Nervenendigungen im Herzen bei Amphibien nnd Säugetieren. Ebenda, Bd. X, Nr. 23, S. 750-760. 1895.

Stieda, L.: Studien über den Amphioxus lanceolatus. Mém. Acad. sc. St. Petersbourg, VII. Ser., Bd. XIX. 1873.

v. Swirski, G.: Über ein wenig beachtetes Merkmal zur Geschlechtsbestimmung der Rana temporaria (autorum). Centralbl. Phys., S. 412 u. 413.1900 .

Te Gempt, D.: Ein Beitrag zur Lehre von den Nervenendigungen im Bindegewebe. Diss. Kiel 1877.

Us s o w, M.: Über den Bau der sogenannten aagenähnlichen Flecken einiger Knochenfische. Bull. soc. natural. Moscou, S. 79-115. 1879.

Wa:l deyer, W.: Über die Endigungsweise der sensiblen Nerven. Arch. mikr. Anat., Bd. XVII, S. 367-382. 1880. 
Wi1l, J. G.: Einige Bemerkungen über die Vaterschen Körperchen der Vögel. Sitz.-Ber. Akad. Wiss. Wien, math.-nat. Kl., Bd. IV, 1. Abt., S. 213-225. 1850.

Wolff, M.: Über die Ehrlichsche Methylenblaufärbung und über Lage und Bau einiger peripherer Nervenendigungen. Arch. Anat. u. Phys., Anat. Abt., S. 155-188. 1902.

\section{Erklärung der Tafeln XL und XLI.}

Fig. 1. Nervenplexus mit zwei Terminalkörperchen aus dem zwischen den beiden Hornfädenschichten gelegenen Bindegewebe. Unter dem Plexus sind Muskekn (a), Sehnen (b) und Hornfäden (c) sichtbar. Afterflosse von Scylliu m. Osmiumbehandlung; 40f. Vergr.

Fig. 2. Teil eines Nervenplexus mit drei Terminalkörperchen, von welchen eines (A) eine Dreiteilung der zutretenden Nervenfaser aufweist, aus dem an der Oberseite der Radien gelegenen Bindegewebe. Brustflosse von Squatin a. Osmiumbehandlung; $75 \mathrm{f}$. Vergr.

Fig. 3. Zylindrisches Terminalkörperchen aus der Brusttlosse von Scyllium mit zwei seitlich zutretenden Nervenfasern. Nervenfärbung mit Goldchlorid; 110f. Vergr.

Fig. 4: Zwei Terminalkörperchen aus der Brustflosse von Squatina. In das eine Körperchen (A) tritt eine marklose, in das andere (B) treten zwei markhaltige Nervenfasern ein. Silberbehandlung nach Caj a l; 250f. Vergr.

Fig. 5. Ovaler Endkolben aus der Brustflosse von Squatina, welcher noch' mit einem vorbeiziehenden Nervenstämmchen vermittelst eines kurzen Stieles in Verbindung steht, durch welchen mehrere marklose Nervenfäserchen durchtreten. Hämatoxylinfärbung; 250f. Veryr.

Fig. 6. Kugeliges Terminalkörperchen aus der Brustflosse von Scyllium. Behandlung mit Goldchlorid; 250f. Vergr.

Fig. 7. Kugeliger Endkolben aus der Brustflosse von Scyllium. Nach einem Goldpräparate; 320f. Vergr.

Fig. 8. Kugeliger Endkolben aus der Brustflosse von Squatina. Silberbehandlung nach Cajal (Material zwei Jahre früher in Formalin konserviert); $250 \mathrm{f}$. Vergr.

Fig. 9. Zylindrisches Körperchen mit zwei langen zutretenden Nervenfasern aus der Schwanzflosse von Scyllium. Silberbehandlung nach Cajal; $500 \mathrm{f}$. Vergr.

Fig. 10. Birnförmiges Endkörperchen von Scyllium mit zwei kurzen zutretenden Nervenfasern, einer markhaltigen und einer marklosen (nach unten hin zeigte das Körperchen noch eine hier nicht gezeichnete Vorwölbung). Behandlung mit Goldchlorid; 250f. Vergr. 
Fig. 11. Grosses unregelmässig gestaltetes (gelapptes), grösstenteils plattes Terminalkörperchen mit fünf zutretenden Nervenästen aus der Brustflosse von Scyllium. Behandlung mit Goldchlorid; 250f. Vergr.

Fig. 12. Retikuläres Gerüst und Nervenzweige aus einem Endkolben von Scyllinm. Behandlung mit Goldchlorid; 71う̌f. Vergr.

Fig. 13. Geäste einer in viele Nervenpräparate auslaufenden dicken Markfaser aus der Brustflosse ron Torpedo. Nach einem Goldpräparat; $40 \mathrm{f}$. Vergr.

Fig. 14. Zwei pinselförmige Endigungen aus der Brustflosse von Torpedo. Behandlung mit Goldchlorid; 250 f. Vergr.

Fig. 15 u. 16. Markloses Geäst aus einem Nervenendapparat der Brustflosse von Torpedo. Goldpräparat; in Fig. $1 \check{\partial} 490 \mathrm{f}$, in Fig. $16270 \mathrm{f}$. Vergr. 